\title{
Ultrasmall polymeric nanocarriers for drug delivery to podocytes in kidney glomerulus
}

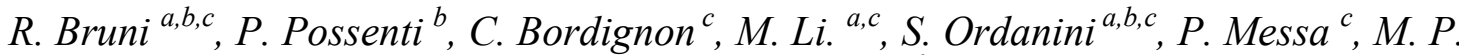 \\ Rastaldi $^{c}, F$. Cellesi ${ }^{*}$ a,b,c
}

a Fondazione CEN - European Centre for Nanomedicine, Piazza Leonardo da Vinci 32, 20133 Milan, Italy

b Dipartimento di Chimica, Materiali ed Ingegneria Chimica "G. Natta". Politecnico di Milano, Via Mancinelli 7, 20131 Milan, Italy

${ }^{\mathrm{c}}$ Renal Research Laboratory, Fondazione IRCCS Ca' Granda Ospedale Maggiore Policlinico, Via Pace 9, 20122 Milan, Italy

keywords: podocytes, kidney, nanoparticles, star polymers, dexamethasone, glomerular filtration barrier

*To whom correspondence should be addressed. E-mail: francesco.cellesi@polimi.it

\begin{abstract}
We explored the use of new drug-loaded nanocarriers and their targeted delivery to the kidney glomerulus and in particular to podocytes, in order to overcome the failure of current therapeutic regimens in patients with proteinuric (i.e. abnormal amount of proteins in the urine) diseases. Podocytes are glomerular cells which are mainly responsible for glomerular filtration and are primarily or secondarily involved in chronic kidney diseases. Therefore, the possibility to utilise a podocyte-targeted drug delivery could represent a major breakthrough in kidney disease research, particularly in terms of dosage reduction and elimination of systemic side effects of current therapies. Four-arm star-shaped polymers, with/without a hydrophobic poly- $\varepsilon$-caprolactone core and a brush-like polyethylene glycol (PEG) hydrophilic shell, were synthesised by controlled/living polymerisation (ROP and ATRP) to allow the formation of stable ultrasmall colloidal nanomaterials of tuneable size $(5-30 \mathrm{~nm})$, which are able to cross the glomerular filtration barrier (GFB). The effects of these nanomaterials on glomerular cells were evaluated in vitro. Nanomaterial accumulation and permeability in the kidney glomerulus were also assessed in mice under physiological and pathological conditions. Drug (dexamethasone) encapsulation was performed in order to test
\end{abstract}


loading capacity, release kinetics, and podocyte repairing effects. The marked efficacy of these drug-loaded nanocarriers in repairing damaged podocytes may pave the way for developing a cell-targeted administration of new and traditional drugs, increasing efficacy and limiting side effects.

\section{Introduction}

Chronic kidney diseases (CKD) are recognised as a major health threat worldwide. Over 10\% of the global population is currently affected by $\mathrm{CKD}[1]$, and this number is expected to steadily increase in the next years [2]. Therapies which are able to treat or slow the progression of kidney damage are still limited[3, 4]; steroids, immunosuppressive agents, and drugs interfering with the renin-angiotensin system cause a number of severe side effects, particularly when a systemic prolonged administration is required. When therapies fail, renal damage inevitably progresses to end stage renal failure, with the need of life-saving renal replacement therapies, which are charged with human and social high costs. Therefore, research is necessary to provide complete information about kidney cell physiology, to unveil disease mechanisms, and to design new and more specific therapies[5]. Technological progresses in nanomedicine already offer the possibility to plan a cell targeted administration of new and traditional drugs, increasing specific efficacy and limiting side effects[6]. Recent advances demonstrated how the majority of kidney diseases are characterised by damage of podocytes in the GFB[7]. Podocytes are highly specialised polarised cells composed by a cell body that bulges into the urinary space, and foot processes which interdigitate with neighbouring cells to completely enwrap the glomerular basement membrane[8]. Podocytes are known to be the primary glomerular target for different types of injuries, such as toxic, metabolic, hemodynamic, oxidant, and immune injury[9], therefore they are primarily or secondarily involved in all glomerular renal diseases. When podocytes work less efficiently due to stress or damage, proteinuria - the loss of proteins in the urine - and glomerular 
dysfunction inevitably take place. If not promptly treated, these conditions lead to progression of glomerular damage and renal failure[8]. Most interestingly, experimental results have also demonstrated that all drugs which are currently used to treat or slow progression of glomerular damage, including Angiotensin-converting enzyme (ACE) inhibitors[10], steroids[11], cyclosporine $\mathrm{A}[9]$, and rituximab[12], have a direct action on podocytes[12-14]. Therefore, the possibility to utilise a podocyte specific delivery of these therapies could be beneficial in terms of dosage reduction and elimination of systemic side effects[15].

The most significant challenge in targeting podocytes is to design engineered nanocarriers which facilitate drug permeation through the GFB $[16,17]$. This biological barrier is a threelayer structure composed of fenestrated glomerular endothelial cells (with pores diameters in the range of $60-80 \mathrm{~nm}$ ), podocytes (with interdigitating foot processes that form filtration slits of $32 \mathrm{~nm}$ ) and glomerular basement membrane between the two cellular layers (rich in heparin sulfate and charged proteoglycans which provides size and charge selectivity)[18]. The glomerular filtration apparatus, taken in its entirety, possesses an effective size cut-off of 6-10 $\mathrm{nm}[19,20]$ (still highly debated in the context of renal function and glomerular pathologies). This size range is generally too small for the permeation of many nanocarriers, including several proteins, biomedical nanoparticles and liposomes. Taking into account these limitations, our approach focused on the design of ultrasmall colloidal polymeric nanomaterials able to permeate through the glomerular barrier (which may also increase its size cut-off under pathological conditions[21]), and reach podocytes.

A library of multiarm amphiphilic polymers were synthesised by Atom Transfer Radical Polymerisation (ATRP) of PEG-methacrylate, starting from either commercial 4-Arm ATRP initiators or custom-made multiarm poly( $\varepsilon$-caprolactone) macroinitiators. When dispersed in 
aqueous solutions, these macromolecules are able to form ultrasmall nanocarriers, stabilised by a dense hydrophilic corona of comb-like PEG (Scheme 1).

ATRP kinetics, reaction conditions, degree of polymerisation and final molecular weight distributions were optimised in order to obtain nearly monodisperse polymers of well-defined structure and molecular weight, and generate nanocarriers of uniform and tuneable particle size.

A subset of polymers with optimal physicochemical properties was identified and further used for biological tests. In particular, nanomaterials of target size $<30 \mathrm{~nm}$ (i.e. compatible with kidney filtration) were selected.

A hydrophobic drug, dexamethasone (DEX), was successfully encapsulated in the nanoparticle core and release profiles were analysed under sink condition.

In vitro tests on podocytes were carried out to exclude polymer cytotoxicity and possible damage to cell cytoskeleton.

Podocyte repair by controlled nanodelivery of DEX was assessed. We took advantage of a recently developed 3D in vitro system, based on a co-culture of endothelial cells and podocytes[22-24], in mimicking the mechanisms of nanoparticle interaction with glomerular cells and the repair of the filtration barrier. Finally, in vivo tests on healthy and proteinuriainduced mice were carried out to investigate the biodistribution of these nanomaterials following intravenous administration, and their capacity to permeate through GFB and accumulate in urine. 


\section{Materials and Methods}

$\varepsilon$-Caprolactone $97 \%$, Pentaerythritol $>99 \%$ (PTOL), Tin(II) 2-ethylhexanoate $92-100 \%$ ( $\left.\mathrm{Sn}(\mathrm{Oct})_{2}\right), \alpha$-Bromoisobutyryl bromide 98\% (BiBB), Triethylamine $>99 \%$ (TEA), Sodium Sulfate $>99 \%$, Poly(ethylene glycol) methyl ether methacrylate $\mathrm{M}_{\mathrm{n}} 500$ (PEGMA), Copper (I) Bromide 98\% (CuBr), 1,1,4,7,10,10-Hexamethyltriethylenetetramine 97\% (HMTETA), Pentaerythritol tetrakis(2-bromoisobutyrate) 97\%, Dichlorometane $>99 \%(\mathrm{DCM})$, Isopropyl alcohol (IPA) $>99.8 \%$, Methanol $>99.8 \%$, Toluene $>99.7 \%$, Tetrahydrofuran (THF) (HPLC grade, inhibitor free, 99.9\%) Diethylether $>99.5 \%$, Acetonitrile $(\mathrm{ACN})>99.5 \%$, Ethylacetate $>99.5 \%$, Acetone 99.5\%, Dimethyl Sulfoxide 99.9\%, 2-Hydroxyethyl methacrylate 97\% (HEMA), Rhodamine B 95\% (RhB), N,N'-Dicyclohexylcarbodiimide 99\% (DCC), 4(Dimethylamino)pyridine 98\% (DMAP), Pyrene 99\%, Sodium Chloride 99\%, Potassium Chloride 99\%, Sodium phosphate dibasic dihydrate 98.5\%, Potassium phosphate monobasic 98\%, Dexamethasone (DEX) 98\%, Deuterochloroform 99.8\%, Dimethyl sulfoxide-d6 100\% were all purchased from Sigma (Italy) and used as received without further purification unless stated otherwise. MilliQ water was obtained by filtration of Helix 5 water using Easy Millipore System. Dialysis regenerated cellulose tubular membrane with 3500 MWCO were purchased by Orange Scientific (Belgium). $0.45 \mu \mathrm{m}$ syringe nylon filter were purchased by Teknokroma (Italy).

\subsection{Characterisation}

The number-average molecular weight $\left(M_{\mathrm{n}, \mathrm{GPC}}\right)$ values and dispersity $\left(\mathrm{Ð}=M_{\mathrm{w}} / M_{\mathrm{n}}\right)$ values of the polymers were evaluated using a Jasco LC-2000Plus gel permeation chromatograph 
(GPC) equipped with a refractive index detector (RI-2031Plus, Jasco) using 3 Agilent PL gel columns, $5 \mu \mathrm{M}$ particle size, $300 \times 7.5 \mathrm{~mm}$ (MW range: $5 \times 10^{2}$ to $17 \times 10^{5} \mathrm{~g} \mathrm{~mol}^{-1}$ ). THF was chosen as eluent at a flow rate of $0.5 \mathrm{~mL} \mathrm{~min}^{-1}$ at $35{ }^{\circ} \mathrm{C}$. The GPC samples $(4 \mathrm{mg} / \mathrm{mL}$ in THF) were injected using a Jasco AS-2055Plus autosampler. The instrument was calibrated using polystyrene standards.

${ }^{1} \mathrm{H}$ NMR spectra were recorded on a Bruker Avance $400 \mathrm{MHz}$ and $500 \mathrm{MHz} \mathrm{NMR}$ instruments. The solvent residual peak was used as internal standard.

IR spectra was registered on a Nicolet iS 50 FTIR spectrometer (Thermo Scientific).

Transmission Electron Microscopy (TEM) analyses were carried out with a JOEL HR-TEM (Philips) with liquid nitrogen grid cooler. TEM images were obtained using $80 \mathrm{kV}$ electric gun power and CCD detector. A small volume $(\sim 5 \mu \mathrm{L})$ of polymer suspensions $(0.1 \mathrm{mg} / \mathrm{mL})$ were spotted on carbon coated copper grid 400 mash using uranyl acetate as negative stain at $3 \% \mathrm{w} / \mathrm{v}$ in dark room.

Particle size distribution, average size, polydispersity index (PDI) of the colloidal nanocarriers in aqueous suspensions (1 mg polymer dispersed in $1 \mathrm{~mL}$ PBS $10 \mathrm{mM} \mathrm{pH} \mathrm{7.4)}$ at different temperatures $\left(10,25,37^{\circ} \mathrm{C}\right)$ were evaluated via Dynamic Light Scattering (DLS, Malvern Zetasizer Nano, Backscattered Angle $173^{\circ}$ ).

Fluorescence analyses were performed with a Jasco FP-8500 spectrofluorometer in order to evaluate the emission of HEMA-Rhodamine fluorescent dye and to determine the apparent Critical Micelle Concentration (CMC) of the polymers by using a pyrene fluorescent probe (see Supplementary Material).

\subsection{General procedure for synthesis of HEMA-Rhodamine B (HEMA-RhB)}

$1 \mathrm{~g}$ of RhB (2.1 mmol, 1 eq.) together with $0.325 \mathrm{~g}$ of 2-Hydroxyethyl methacrylate (HEMA, $2.5 \mathrm{mmol}, 1.2$ eq.) were dissolved in $20 \mathrm{~mL}$ acetonitrile under magnetic stirring at room 
temperature. $0.43 \mathrm{~g}$ of DCC (2.1 mmol, 1 eq.) and $13 \mathrm{mg}$ of DMAP (106 mmol, 50 eq.) were dissolved in $20 \mathrm{~mL}$ of acetonitrile; this solution was added dropwise to the reacting mixture in 20 minutes. The reaction was carried out in the dark at $40{ }^{\circ} \mathrm{C}$ under magnetic stirring and nitrogen atmosphere for $24 \mathrm{~h}$ and then quenched in an ice bath for 10 minutes. Dicyclohexylurea, the side product of the coupling reaction, was eliminated from the solution through filtration and finally acetonitrile was removed under reduced pressure.

The solid was re-dispersed in ethyl acetate and a diluted solution of $\mathrm{NaHCO}_{3}$. The water phase was isolated and washed three times with fresh ethyl acetate and finally saturated with $\mathrm{NaCl}$, while the $\mathrm{pH}$ was maintained neutral by adding drops of a $1 \mathrm{M} \mathrm{HCl}$ solution. The product was extracted with a mixture of DCM/IPA 1:2 v/v. The organic phase was collected and dried with sodium sulphate, and the solvent was removed by rotary evaporator. The solid was dissolved in small amount of methanol and precipitated into cold diethylether (Yield = $80 \%)$.

${ }^{1} \mathrm{H}$ NMR (400 MHz, DMSO) $\delta 8.26\left(\mathrm{dd}, J=7.8 \mathrm{~Hz}, J=0.9 \mathrm{~Hz}, 1 \mathrm{H}, \mathrm{H}_{\text {benzoate }}\right), 7.92$ (ddd, $J=$ $7.8 \mathrm{~Hz}, J=7.8 \mathrm{~Hz}, J=0.9 \mathrm{~Hz}, 1 \mathrm{H}, \mathrm{H}_{\text {benzoate }}$ ), 7.85 (ddd, $J=7.8 \mathrm{~Hz}, J=7.8 \mathrm{~Hz}, J=0.9 \mathrm{~Hz}$, $\left.1 \mathrm{H}, \mathrm{H}_{\text {benzoate }}\right), 7.50$ (dd, $\left.J=7.8 \mathrm{~Hz}, J=0.9 \mathrm{~Hz}, 1 \mathrm{H}, \mathrm{H}_{\text {,benzoate }}\right), 7.07$ (dd, $J=9.5 \mathrm{~Hz}, J=2.3 \mathrm{~Hz}$, 2H, $\left.\mathrm{H}_{\text {Xan }}\right), 6.98$ (d, $\left.J=9.5 \mathrm{~Hz}, 2 \mathrm{H}, \mathrm{H}_{\text {Xan }}\right), 6.94$ (d, $\left.J=2.3 \mathrm{~Hz}, 2 \mathrm{H}, \mathrm{H}_{\text {Xan }}\right), 5.80(\mathrm{~s}, 1 \mathrm{H}$, $\left.\mathrm{CCH}_{3} \mathrm{CH}_{2}\right), 5.58\left(\mathrm{~s}, 1 \mathrm{H},-\mathrm{CCH}_{3} \mathrm{CH}_{2}\right), 4.30-4.16\left(\mathrm{~m}, 2 \mathrm{H},-\mathrm{C}(\mathrm{O}) \mathrm{OCH}_{2} \mathrm{CH}_{2} \mathrm{O}-\right), 4.03-3.91$ (m, 2H, - $\left.\mathrm{C}(\mathrm{O}) \mathrm{OCH}_{2} \mathrm{CH}_{2} \mathrm{O}-\right), 3.64$ (q, $\left.J=6.9 \mathrm{~Hz}, 8 \mathrm{H},-\mathrm{NCH}_{2}-\right), 1.75$ (s, 3H, $-\mathrm{CCH}_{3} \mathrm{CH}_{2}$ ), 1.21 $\left(\mathrm{t}, J=6.9 \mathrm{~Hz}, 12 \mathrm{H},-\mathrm{NCH}_{2} \mathrm{CH}_{3}\right) \cdot{ }^{13} \mathrm{C} \mathrm{NMR}(100 \mathrm{MHz}, \mathrm{DMSO}) \delta 166.11(\mathrm{C}=\mathrm{O}), 164.55$ $(\mathrm{C}=\mathrm{O}), 157.54\left(\mathrm{C}_{\text {quat }}\right), 157.03\left(\mathrm{C}_{\text {quat }}\right), 155.10\left(\mathrm{C}_{\text {quat }}\right), 135.20\left(\mathrm{C}_{\text {quat }}\right), 133.33,133.18\left(\mathrm{C}_{\text {benzoate }}\right)$, 130.94, 130.84 ( $\left.\mathrm{C}_{\text {benzoate }}, \mathrm{C}_{\text {Xan }}\right), 130.50,130.48$ ( $\left.\mathrm{C}_{\text {benzoate }}\right), 129.09\left(\mathrm{C}_{\text {quat }}\right), 125.98\left(-\mathrm{CCH}_{3} \mathrm{CH}_{2}\right)$, $114.54\left(\mathrm{C}_{\text {Xan }}\right), 112.85\left(\mathrm{C}_{\text {quat }}\right), 95.87$ ( $\left.\mathrm{C}_{\text {Xan }}\right), 63.01,62.29,61.97\left(-\mathrm{C}(\mathrm{O}) \mathrm{OCH}_{2} \mathrm{CH}_{2} \mathrm{O}-\right), 45.29$ ($\left.\mathrm{NCH}_{2} \mathrm{CH}_{3}\right), 17.79\left(-\mathrm{CCH}_{3} \mathrm{CH}_{2}\right), 12.38\left(-\mathrm{NCH}_{2} \mathrm{CH}_{3}\right)$.

\subsection{Synthesis of 4-arm poly(E-caprolactone) (A4CL10 and A4CL20)}

4-arm poly(ع-caprolactone) was synthesised by ring opening polymerisation in bulk conditions at $130{ }^{\circ} \mathrm{C}$, using pentaerythritol as multi-arm initiator and tin(II) 2-ethylhexanoate 
as catalyst. $20 \mathrm{~g}$ of $\varepsilon$-caprolactone monomer and pentaerythritol were added to a flask and stirred for $15 \mathrm{~min}$ at $130{ }^{\circ} \mathrm{C}$ to obtain a homogeneous solution. The initiator amount was calculated according to the target degree of polymerisation $([\mathrm{M}] /[\mathrm{I}]=10$ for $\mathrm{A} 4 \mathrm{CL} 10$ polymer, and $[\mathrm{M}] /[\mathrm{I}]=20$ for A4CL20 polymer, where $[\mathrm{M}]$ and $[\mathrm{I}]$ are the concentrations of the monomer and the $\mathrm{OH}$ - functional groups in pentaerythritol, respectively). The polymerisation started by adding tin(II) 2-ethylhexanoate (1/200 mol catalyst / mol OH- functional groups). The reaction mixture was stirred for $8 \mathrm{~h}$ at $130{ }^{\circ} \mathrm{C}$, then cooled down, and the polymer was purified by precipitation from a concentrated dichloromethane solution into hexane. The final solid product was dried via rotary evaporator (yields $>95 \%$ ).

${ }^{1} \mathrm{H}$ NMR $\left(400 \mathrm{MHz}, \mathrm{CDCl}_{3}\right) \delta 4.05\left(\mathrm{t}, J=6.7 \mathrm{~Hz}, 2 \mathrm{H}\right.$ x $\left.(\mathrm{n}-1),-\mathrm{CH}_{2} \mathrm{CH}_{2} \mathrm{OC}(\mathrm{O})-\right), 3.63(\mathrm{t}, \mathrm{J}=$ $\left.6.5 \mathrm{~Hz}, 2 \mathrm{H},-\mathrm{CH}_{2} \mathrm{OH}\right), 2.29\left(\mathrm{t}, \mathrm{J}=7.5 \mathrm{~Hz}, 2 \mathrm{H} \mathrm{x} \mathrm{n,}-\mathrm{OC}(\mathrm{O}) \mathrm{CH}_{2} \mathrm{CH}_{2^{-}}\right), 1.71-1.53(\mathrm{~m}, 4 \mathrm{H} \times \mathrm{n},-$ $\left.\mathrm{OC}(\mathrm{O}) \mathrm{CH}_{2} \mathrm{CH}_{2^{-}}, \mathrm{CH}_{2} \mathrm{CH}_{2} \mathrm{OC}(\mathrm{O})-\right), 1.44-1.34\left(\mathrm{~m}, 2 \mathrm{H} \mathrm{x} \mathrm{n},-\mathrm{CH}_{2} \mathrm{CH}_{2} \mathrm{CH}_{2}-\right)$, where $\mathrm{n}$ is the degree of polymerisation.

FT-IR: $2948\left(v_{\mathrm{as}} \mathrm{CH}_{2}\right) ; 2864\left(v_{\mathrm{s}} \mathrm{CH}_{2}\right) ; 1721(v \mathrm{C}=\mathrm{O}) ; 1293(\mathrm{C}-\mathrm{O}$ and $\mathrm{C}-\mathrm{C}) ; 1238\left(\mathrm{v}_{\mathrm{as}} \mathrm{COC}\right) ; 1182$ (v OC-O); $1168\left(v_{\mathrm{s}} \mathrm{COC}\right)$.

\subsection{Synthesis of $A 4 C L 10 B r$ and A4CL2OBr macroinitiators}

Functionalisation of A4CL10 and A4CL20 was obtained by esterification of the $\mathrm{OH}$ terminal group with $\alpha$-bromoisobutyryl bromide (BIBB).

$5 \mathrm{~g}$ of polymer was dissolved in $25 \mathrm{~mL}$ of toluene and mixed with triethylamine $\left(\mathrm{Et}_{3} \mathrm{~N}, 3.0\right.$ $\mathrm{mmol} / \mathrm{arm}$ ) into a three-neck flask under nitrogen atmosphere. $3.0 \mathrm{mmol} / \mathrm{arm}$ of BIBB was added dropwise, while the reaction flask was cooled into an ice bath. The reaction was performed under stirring and nitrogen atmosphere at room temperature overnight. The reaction mixture was filtrated through a small pad of neutral alumina column, washing with toluene, to remove triethylammonium chloride, and the solvent evaporated at the rotary evaporator. The resulting viscous oil was dissolved in dichloromethane, washed with water 
( $\mathrm{pH}$ was kept neutral by adding sodium bicarbonate), dried over sodium sulfate and finally precipitated in cold diethyl ether. Conversion $=100 \%$ (from ${ }^{1} \mathrm{H}$ NMR data). Yield $=80 \%$.

${ }^{1} \mathrm{H}$ NMR $\left(400 \mathrm{MHz}, \mathrm{CDCl}_{3}\right) \delta 4.15\left(\mathrm{t}, J=6.5 \mathrm{~Hz}, 2 \mathrm{H},-\mathrm{CH}_{2} \mathrm{OC}(\mathrm{O}) \mathrm{C}\left(\mathrm{CH}_{3}\right)_{2} \mathrm{Br}\right), 4.04(\mathrm{t}, J=$ $\left.6.7 \mathrm{~Hz}, 2 \mathrm{H} x(\mathrm{n}-1),-\mathrm{CH}_{2} \mathrm{CH}_{2} \mathrm{OC}(\mathrm{O})-\right), 2.28$ (t, $J=7.5 \mathrm{~Hz}, 2 \mathrm{H} \mathrm{x} \mathrm{n,}-\mathrm{OC}(\mathrm{O}) \mathrm{CH}_{2} \mathrm{CH}_{2}$ ), 1.90 (s, $\left.6 \mathrm{H},-\mathrm{CH}_{2} \mathrm{OC}(\mathrm{O}) \mathrm{C}\left(\mathrm{CH}_{3}\right)_{2} \mathrm{Br}\right), 1.69-1.58\left(\mathrm{~m}, 4 \mathrm{H} \times \mathrm{n},-\mathrm{OC}(\mathrm{O}) \mathrm{CH}_{2} \mathrm{CH}_{2^{-}},-\mathrm{CH}_{2} \mathrm{CH}_{2} \mathrm{OC}(\mathrm{O})-\right)$, $1.40-1.36\left(\mathrm{~m}, 2 \mathrm{H} \mathrm{x} \mathrm{n},-\mathrm{CH}_{2} \mathrm{CH}_{2} \mathrm{CH}_{2}-\right)$, where $\mathrm{n}$ is the degree of polymerisation.

FT-IR: $2947\left(v_{\mathrm{as}} \mathrm{CH}_{2}\right) ; 2866\left(\mathrm{v}_{\mathrm{s}} \mathrm{CH}_{2}\right) ; 1721\left(\mathrm{v}_{\mathrm{s}} \mathrm{C}=\mathrm{O}\right) ; 1367\left(\mathrm{vsCH}_{3}\right) ; 1292(\mathrm{C}-\mathrm{O}$ and $\mathrm{C}-\mathrm{C})$; $1241\left(v_{\mathrm{as}} \mathrm{COC}\right) ; 1162\left(\mathrm{v}_{\mathrm{s}} \mathrm{COC}\right)$.

\subsection{ATRP of PEGMA from 4-arm initiators}

PEGMA (4.5 g, $9 \mathrm{mmol}$ ), and the 4-arm macroinitiator (either Pentaerythritol tetrakis(2bromoisobutyrate), A4CL10Br or A4CL20Br) were added to a schlenk flask wrapped in aluminum foil, which was evacuated and backfilled with nitrogen three times. The initiator amount was calculated according to the target degree of polymerisation $([\mathrm{M}] /[\mathrm{I}]=5,10,20$, where $[\mathrm{M}] /[\mathrm{I}]$ represent the molar ratio between PEGMA and the single arm ATRP initiator). $\mathrm{CuBr}$, HMTETA and $10 \mathrm{~mL}$ of degassed and inhibitor free THF were finally added to the reactor, which was sealed with a rubber septum. The molar ratios between single-arm initiator, catalyst and ligand was maintained at $[\mathrm{I}]:[\mathrm{CuBr}]:[\mathrm{HMTETA}]=1: 1: 1$ in all polymerisations. When required, a small amount of HEMA-RhB was also added as co-monomer (HEMA-RhB/M = 1:100 mol/mol) to obtain fluorescent polymers for biological experiments.

The reaction mixture was stirred for 6 hours at $50{ }^{\circ} \mathrm{C}$ under nitrogen atmosphere, and then quenched by exposing it to air and cooling the flask with an ice bath. The mixture was passed through a pad of neutral alumina to remove the catalyst. The filtrate was concentrated by rotary evaporator and the residue was precipitated in cold diethyl ether. The polymers obtained were dried under vacuum (Yield $>80 \%$ ), and characterised by ${ }^{1} \mathrm{H}$ NMR and GPC.

${ }^{1} \mathrm{H}$ NMR (400 MHz, $\left.\mathrm{CDCl}_{3}\right) \delta 4.16-3.99\left(\mathrm{~m}, 2 \mathrm{H}\right.$ x n, $\left.-\mathrm{CH}_{2} \mathrm{CH}_{2} \mathrm{OC}(\mathrm{O})-\right), 3.75-3.50(\mathrm{~m}$, $\left.\mathrm{H}_{\text {PEGMA }} \times \mathrm{p},-\mathrm{OCH}_{2} \mathrm{CH}_{2} \mathrm{O}-\right), 3.37\left(3 \mathrm{H} \times \mathrm{p},-\mathrm{OCH}_{3}\right), 2.29(\mathrm{t}, J=7.5 \mathrm{~Hz}, 2 \mathrm{H} \times \mathrm{n}$, $\left.\mathrm{OC}(\mathrm{O}) \mathrm{CH}_{2} \mathrm{CH}_{2-}\right), 1.72-1.57\left(\mathrm{~m}, 4 \mathrm{H} \mathrm{x} \mathrm{n,}-\mathrm{OC}(\mathrm{O}) \mathrm{CH}_{2} \mathrm{CH}_{2-},-\mathrm{CH}_{2} \mathrm{CH}_{2} \mathrm{OC}(\mathrm{O})-\right), 1.45-1.33$ 
(m, $\left.2 \mathrm{H} \mathrm{x} \mathrm{n,}-\mathrm{CH}_{2} \mathrm{CH}_{2} \mathrm{CH}_{2}-\right), 1.16-0.80\left(\mathrm{~m}, 3 \mathrm{H} \mathrm{x} \mathrm{p}, \mathrm{CH}_{3 \text { backbone }}\right)$, where $\mathrm{n}$ is the $\mathrm{CL}$ degree of polymerisation and $\mathrm{p}$ is the PEGMA degree of polymerisation.

\subsection{Characterisation of PEGMA ATRP kinetics.}

PEGMA polymerisations were carried out as described above. Aliquots (100 $\mu \mathrm{L}$ sample) were withdrawn from the reaction mixture at intervals during the course of the reaction, filtered through a pad of neutral alumina and analysed by ${ }^{1} \mathrm{H}$ NMR spectroscopy using $\mathrm{CDCl}_{3}$ as deuterated solvent to measure conversion and to examine the evolution of molecular weight. The concentrations of the reactants (monomer vinyl signals at $\delta=5.5$ and $6.0 \mathrm{ppm}$ $\mathrm{CH}_{2}=\mathrm{C}\left(\mathrm{CH}_{3}\right)-$ ) compared to the product (broad singlet at $\delta=4.07,-\mathrm{CH}_{2} \mathrm{C}=\mathrm{O}$ ) were calculated with respect to reaction time by ${ }^{1} \mathrm{H}$ NMR analysis.

\subsection{Dexamethasone (DEX) loading and release}

$5 \mathrm{mg}$ of DEX and $50 \mathrm{mg}$ of polymer were dissolved in $1 \mathrm{~mL}$ of acetone under magnetic stirring $(500 \mathrm{rpm})$ at room temperature. Then the solution was dropped in to $1 \mathrm{~mL}$ of Milli-Q water under stirring. Evaporation of volatile solvent was performed by rotary evaporator at 40 ${ }^{\circ} \mathrm{C}$, and the suspension was filtered through a $0.45 \mu \mathrm{m}$ syringe nylon filter to remove any precipitate formed by oversaturation of DEX. After DEX loading, samples were characterised by dynamic light scattering $(1 \mathrm{mg} / \mathrm{mL})$ to evaluate changes in the hydrodynamic diameters. Afterwards, samples were freeze dried, weighted to determine the mass of the solid phase, redissolved in $2 \mathrm{ml}$ of acetonitrile, diluted 1:10 and analysed by HPLC to estimate the amount of encapsulated DEX in each polymer. The encapsulation efficiency (EE) and drug loading (DL) were calculated as follows: $\mathrm{EE}=($ weight of DEX loaded $[\mathrm{mg}]) /($ total weight of DEX used $[\mathrm{mg}]), \mathrm{DL}=($ weight of DEX loaded $[\mathrm{mg}]) /($ total weight of the solid phase $[\mathrm{mg}])$. 
Release studies were conducted via HPLC by dialyzing $3 \mathrm{~mL}$ of DEX-loaded NPs in water (prepared starting from $15 \mathrm{mg}$ of DEX and $150 \mathrm{mg}$ of polymer, according to the loading procedure described above) against $200 \mathrm{~mL}$ of PBS buffer $(10 \mathrm{mM}, \mathrm{pH} 7.4)$ at $37{ }^{\circ} \mathrm{C}$ (regenerated cellulose dialysis membrane, 3500 Da cut-off). At selected times, small aliquots $(100 \mu \mathrm{L})$ were withdrawn and replaced with an equal volume of PBS. The samples were analysed by HPLC to determine the concentration of DEX.

The HPLC system (Jasco) was equipped with a Restek C18 column and a photodiode array PDA detector. Detector wavelength was set at $254 \mathrm{~nm}$, the mobile phase was composed of water and acetonitrile $(70 / 30 \mathrm{v} / \mathrm{v})$ in isocratic condition at a flow rate of $1 \mathrm{~mL} / \mathrm{min}$ at $30{ }^{\circ} \mathrm{C}$.

\subsection{LDH Cytotoxicity tests}

NPs cytotoxicity was measured using LDH-Cytotoxicity Colorimetric Assay Kit (BioVision Incorporated). Briefly $6000-8000$ per well of conditionally immortalised murine kidney podocytes SV1 (CLS Cell Line Service Ltd, Eppelheim, Germany) were plated on a 96-well plate and cultured at $37{ }^{\circ} \mathrm{C}$ in DMEM/F-12 medium supplemented with $10 \% \mathrm{FCS}, 5 \mu \mathrm{g} / \mathrm{mL}$ transferrin, $10^{-7} \mathrm{M}$ hydrocortisone, $5 \mathrm{ng} / \mathrm{mL}$ sodium selenite, $0.12 \mathrm{U} / \mathrm{mL}$ insulin, $100 \mathrm{U} / \mathrm{mL}$ penicillin, $100 \mathrm{mg} / \mathrm{mL}$ streptomycin, $2 \mathrm{mM} \mathrm{L}$-glutamine, and without $\gamma$-interferon for 3-4 days. Then, the culture medium was replaced by medium containing different concentrations of polymers $(0.01-2 \mathrm{mg} / \mathrm{mL})$ which was incubated with cells for 24 hours. For positive control (high control), $10 \mu \mathrm{L}$ of cell Lysis solution was added and incubated for 24 hours, while the low control was referred to cells incubated only with standard medium. At the end of incubation, the plate was gently shacked for some minutes and centrifuged at $600 \mathrm{x} \mathrm{g}$ for $10 \min .10 \mu \mathrm{L}$ of culture medium from each well was transferred into a new optically clear 96-well plate, and $100 \mu \mathrm{L}$ of LDH Reaction Mix was added to each well and incubated at room temperature for 1 to 2 hours (depending on the colour development). The absorbance of 
all controls and samples was measured with $450 \mathrm{~nm}$ filter using SAFAS spectrophotometry (Monaco). The cytotoxicity was calculated using the equation: Normalised Cytotoxicity = (Test sample-Low control)/( High control-Low control); Low control: normal cells; High control: cells treated with lysis buffer.

\subsection{Phalloidin-FITC Staining}

Podocytes cultured on coverslips were fixed with $4 \%$ of Paraformaldehyde at room temperature for 10 minutes. After washing, cells were permeabilised with $0.3 \%$ of Triton in PBS for 5 minutes and incubated with $1 \%$ of BSA in PBS at room temperature for 30 minutes. Phalloidin-FITC (Sigma-Aldrich) at 1:100 dilution together with DAPI at 1:1000 dilution (Sigma-Aldrich) was added and the cells were incubated for 1 hour, in order to stain actin fibres of podocyte cytoskeleton. After 3 times washing with PBS, the cells were mounted with Fluorsave aqueous mounting medium (Merck, Milano, Italy). Images were acquired by Zeiss AxioObserver microscope equipped with high resolution digital videocamera (AxioCam, Zeiss) and Apotome system for structured illumination, and recorded by AxioVision software 4.8.

\subsection{Primary Podocytes Culture}

For primary podocytes cultures, kidneys taken from 7 - to 10 -d-old C57BL/6 mice were decapsulated and washed in cold $\mathrm{Ca}^{2+}$ and $\mathrm{Mg}^{2+}$ free Hanks medium. Glomeruli were isolated by sieving, then seeded in culture flasks (Corning, Sigma-Aldrich) pre-coated with collagen type IV (Sigma-Aldrich) at $37{ }^{\circ} \mathrm{C}$ in $5 \% \mathrm{CO}_{2}$ atmosphere and covered by DMEM-F12 medium supplemented with $10 \% \mathrm{FCS}, 5 \mu \mathrm{g} / \mathrm{mL}$ transferrin, $10^{-7} \mathrm{M}$ hydrocortisone, $5 \mathrm{ng} / \mathrm{mL}$ sodium selenite, $0.12 \mathrm{U} / \mathrm{mL}$ insulin, $100 \mathrm{U} / \mathrm{mL}$ penicillin, $100 \mathrm{mg} / \mathrm{mL}$ streptomycin, $2 \mathrm{mM} \mathrm{L}$ glutamine. After 1 week, first-passage podocytes were separated from glomeruli by an 
additional sieving through the $36-\mu \mathrm{m}$ mesh. Second passage podocytes were seeded on flasks and thermanox coverslips (Nunc, VWR Int., Milan, Italy). Cell characterisation was performed by morphology and immunofluorescence, using podocyte (nephrin, podocin), epithelial (cytokeratins), smooth muscle ( $\alpha$-smooth muscle actin), and endothelial cell (CD31) markers.

\subsection{DEX release on podocytes}

$2 \times 10^{4} \mathrm{SV} 1$ cells or $1 \times 10^{5}$ primary podocytes were plated on a $35 \mathrm{~mm}$ petri containing 4 cell culture coverslips and cultured at $37^{\circ} \mathrm{C}$ for 3-4 days. Afterwards, cells were incubated with $0.8 \mu \mathrm{M}$ Adriamycin (ADR, Sigma- Aldrich) in cell culture medium for 24 hours. After incubation, ADR was replaced by fresh medium (as control group) or medium with different concentration of NPs loaded with DEX and incubated for another 24 or 48 hours. Finally, cells were washed 3 times with PBS, fixed with 4\% of Paraformaldehyde and stained with DAPI and phalloidin-FITC, as described above.

\subsection{Analysis of fibre orientation}

In order to extract quantitative data on actin fibre orientation in podocytes, images from phalloidin-stained cells were processed by ImageJ software [25] supported with FibrilTool plugin [26], which was designed to quantify the orientation and anisotropy of fibrillary structures in raw images. Once a region of interest (ROI) was selected (corresponding to a single cell), the Anisotropy score was calculated to evaluate the green fibrils orientation in a preferred direction. The following convention was used: 0 for no order (purely isotropic array of fibrils) and 1 for perfectly ordered (parallel fibrils, purely anisotropic array)[26].

\subsection{Co-culture system and permeability assessment}


$1 \mu \mathrm{m}$ porous Biopore membranes (Millicell hanging cell culture inserts, made of Polyethylene Terephthalate (PET), Millipore, Milan, Italy) were coated on both sides with collagen type IV, as previously reported[23, 24]. $1.5 \times 10^{5}$ of endothelial cells (EOMA, CRL2586, LGC Standards S.r.l., Italy) were seeded on the lower side of the membrane and exposed to VEGF $5 \mathrm{ng} / \mathrm{mL}$ for one week before $65000 \mathrm{SV} 1$ cells were seeded on the upper side of the membrane and incubated in their own medium.

In order to assess albumin permeability, cells were carefully washed on both sides with PBS. Podocyte damage was induced by adding to the podocyte medium Adriamycin $(0.8 \mu \mathrm{M})$ and incubating for 24 hours. Then, the upper (podocyte) compartment was filled with either standard medium (as control) or DMEM/F-12 containing DEX-loaded A4CL10PEG20 nanoparticles (DEX $1.5 \% \mathrm{w} / \mathrm{w}$, total nanoparticle concentration range $0.4 \div 20 \mu \mathrm{M}$ ) and the system was incubated for $24 \div 48 \mathrm{hr}$. Afterwards, the lower (endothelial) compartment was filled with DMEM/F12 supplemented with $40 \mathrm{mg} / \mathrm{mL}$ of Bovine serum albumin (BSA, Sigma-Aldrich). Medium was taken from the upper compartment after 2 hours incubation and albumin content was measured by spectrometry using the DC protein assay kit (Bio-Rad, Milano, Italy). Results were expressed as percentage of BSA permeability versus control conditions. Data were presented as mean \pm standard deviation of three different replicates and analysed for statistical significance by Student's t-test. Coomassie-stained gels were used to confirm that BSA was the only protein present in the medium, excluding the contribution from cellular proteins.

\subsection{Biodistribution of nanocarriers in healthy mice}

2-3 month-old male Balb/c mice (Charles River Italia, Calco, Lecco, Italy) were divided into

3 groups (3 mice each). Each group received one type of rhodamine-labelled nanocarrier (A4PEG5, A4PEG20, A4CL10PEG20). $200 \mu \mathrm{L}$ of polymer at concentration of $2 \mathrm{mg} / \mathrm{mL}$ 
(corresponding to $0.4 \mathrm{mg}$ of polymer) in physiological solution $(0.9 \% \mathrm{NaCl})$ was injected via tail vein and housed into a metabolic cage for the collection of urine. Mice were sacrificed on 24 hours after injection, the spleen, liver, lung and kidney were removed and embedded in optimum cutting temperature cryo-embedding matrix (OCT, Tissue-Tek, Electron Microscopy Sciences, Società Italiana Chimici, Roma, Italy), snap-frozen in a mixture of isopentane and dry ice and stored at $-80{ }^{\circ} \mathrm{C}$. Mice which received an injection of physiological solution were used as control.

\subsection{Biodistribution of nanocarriers in mice with Adriamycin nephropathy}

Adriamycin nephropathy was induced by a single injection of $10 \mathrm{mg} / \mathrm{Kg}$ doxorubicin hydrochloride (Sigma) in the tail vein of 3-month-old male Balb/c mice (Charles River Italia, Calco (Lecco), Italy) according to a protocol reported in literature[27]. The presence of urinary albumin was monitored every day by Albustix test (Bayer, Milan, Italy). The 9 mice reaching 4+ albumin values by Albustix were selected and randomised to 3 groups to receive 3 different size of polymeric nanomaterials, following the same protocol used for healthy mice. The urinary samples were collected, mice were sacrificed and the tissues were processed as described above.

\subsection{Fluorescence Microscopy Examination}

5- $\mu$ m-thick tissue cryosections were fixed with $4 \%$ of paraformaldehyde at room temperature for $10 \mathrm{~min}$. Nuclei were stained with 4',6-Diamidino-2-phenylindole (DAPI) at a concentration of of $0.1 \mathrm{mg} / \mathrm{mL}$ in PBS for 30 minutes. Slides were mounted with Fluorsave aqueous mounting medium (Calbiochem, VWR International, Milan, Italy). Images were acquired by a Zeiss Axioscope (40FL microscope), equipped with an AxioCam MRc5 digital 
videocamera and an immunofluorescence apparatus (Carl Zeiss SpA, Arese, Italy). Images were recorded using AxioVision software 4.3.

\subsection{Urine collection and analysis}

The quantity of nanomaterial accumulated in urine was measured using a SAFAS Spectrofluorimetry (SAFAS, Monaco). Briefly, $50 \mu \mathrm{L}$ of urine collected during 24 hours after injection was added into a black 96-well plate and analysed at $\lambda_{\mathrm{ex}}=540 \mathrm{~nm}$ and $\lambda_{\text {em }}=584$ nm. A 1:2 serial dilution from 0.5 to $0.0075 \mathrm{mg} / \mathrm{mL}$ of each polymer dispersed in PBS was used to obtain a calibration curve and evaluate the extinction coefficient, in order to convert absorbance values to concentrations. Urine from mice which did not receive any polymer injection was used for background control. Data were presented as mean \pm standard deviation of three different replicates and analysed for statistical significance by Student's t-test.

2.18 Ethical approval. Animal protocols strictly adhered to the Public Health Service Policy on Humane Care and Use of Laboratory Animals (D.L.116-27/01/1992) and were approved by the Milan University Institutional Care and Ethical Treatment Committee (Prot.N. 07/13). All animals were housed on a 12-h light/dark cycle, and allowed free access to food and water. When appropriate, the animals were sacrificed by decapitation after anaesthesia induced by intraperitoneal injection of $370 \mathrm{mg} / \mathrm{Kg}$ of Chloral hydrate.

\section{Results and discussion}

\subsection{Synthesis and characterisation of the nanomaterials}

Polymeric nanocarriers were designed to obtain a 4-arm comb-like structure composed of a poly(PEGMA) hydrophilic corona (Scheme 1). This hyperbranched structure allows to obtain 
ultrasmall colloidal nanomaterials stabilised by a dense hydrophilic PEG-based shell. In order to enhance the loading efficiency of DEX, a hydrophobic block of poly( $\varepsilon$-caprolactone) was introduced to form a core-shell structure. The polyester core also allowed biodegradability of the nanocarrier.

A
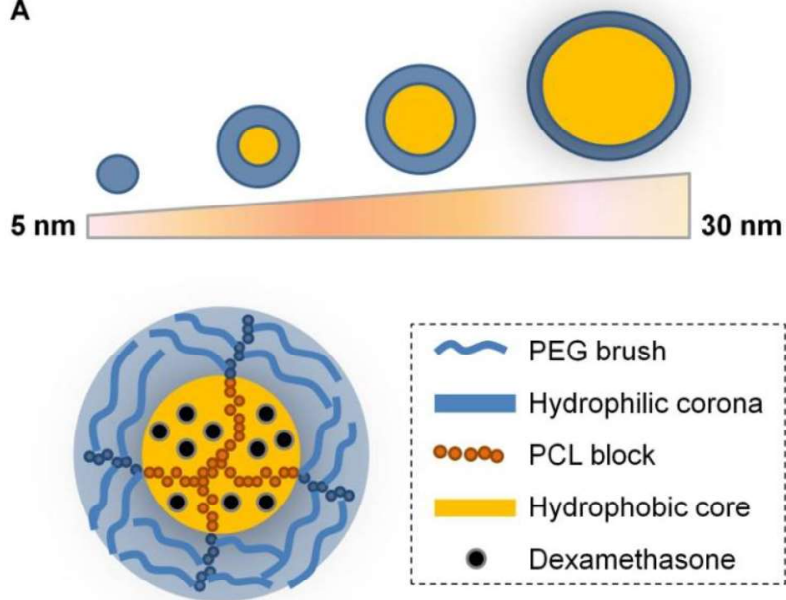

Ultrasmall polymeric nanocarrier

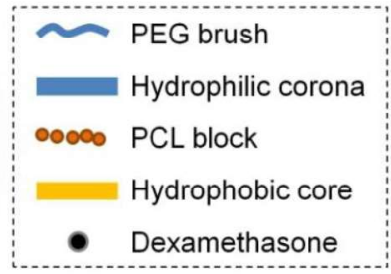

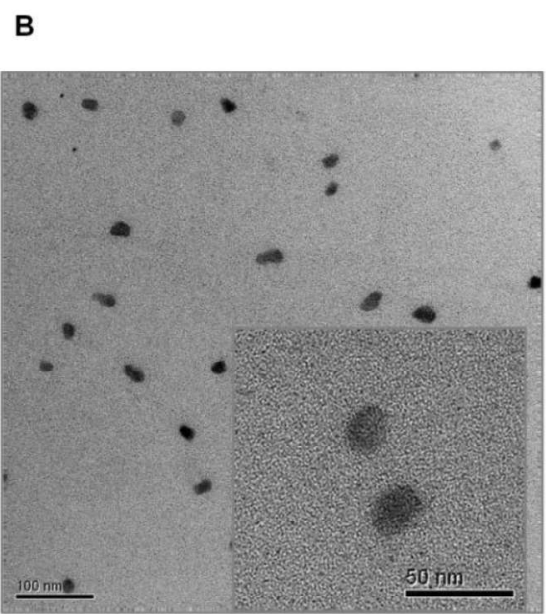

$100 \mathrm{mms}$

Scheme 1. A) Four-arm star-shaped polymers, with/without a hydrophobic PCL core and a brush-like PEG hydrophilic shell, form stable ultrasmall colloidal nanomaterials which are able to encapsulate and release DEX and to cross the GFB. B) TEM image of a polymeric nanocarrier (A4CL10PEG20, scale bar $100 \mathrm{~nm}$ ). Inset: details of the nanocarriers at higher magnification (scale bar $50 \mathrm{~nm}$ ).

Hydrophobic 4-arm poly( $\varepsilon$-caprolactone) (A4CLn, $n=10,20)$ were synthesised by Ring Opening Polymerisation ROP[28] using pentaerythritol initiator (Scheme 2). We obtained full monomer conversion, with controlled molecular weight and low dispersity. The degree of polymerisation (DP 10-20) was clearly regulated by the monomer-initiator molar ratio $[\mathrm{M}] /[\mathrm{I}]$. The $-\mathrm{OH}$ terminal groups of PCL were further converted into bromide ATRP initiators (A4CLnBr) by esterification with 2-bromoisobutyryl bromide. Full degree of functionalisation was obtained (100\% conversion) without affecting polymer DP and 
dispersity Đ (Table 1). The ATRP of PEGMA was carried out in THF using CuBr-HMTETA as catalytic system. Pentaerythritol tetrakis (2-bromoisobutyrate) was used as initiator to obtain 4-arm PEG-based polymer brushes (A4PEGp, $p=5,10,20$ ), whereas the 4-arm macroinitiators $\mathrm{A} 4 \mathrm{CL} 10 \mathrm{Br}$ and $\mathrm{A} 4 \mathrm{CL} 20 \mathrm{Br}$ were used to obtain larger core-shell structures with the general formula A4CLnPEGp (Scheme 2). A high control of the polymerisation kinetics was necessary to obtain a fine tuning of polymer molecular weight with narrow dispersity, since the permeability through the GFB strongly depends on these parameters. According to our preliminary experiments on PEGMA polymerisation in different solvent/catalysts (see Supplementary Material), CuBr-HMTETA in THF at $50{ }^{\circ} \mathrm{C}$ were selected as optimal conditions for ATRP, overcoming the typical limitations of ATRP from multiarm initiators, i.e. partial initiation of the multiarm ATRP sites and possible arm-arm coupling at high conversion, which may lead to broad molecular weight distributions[29].
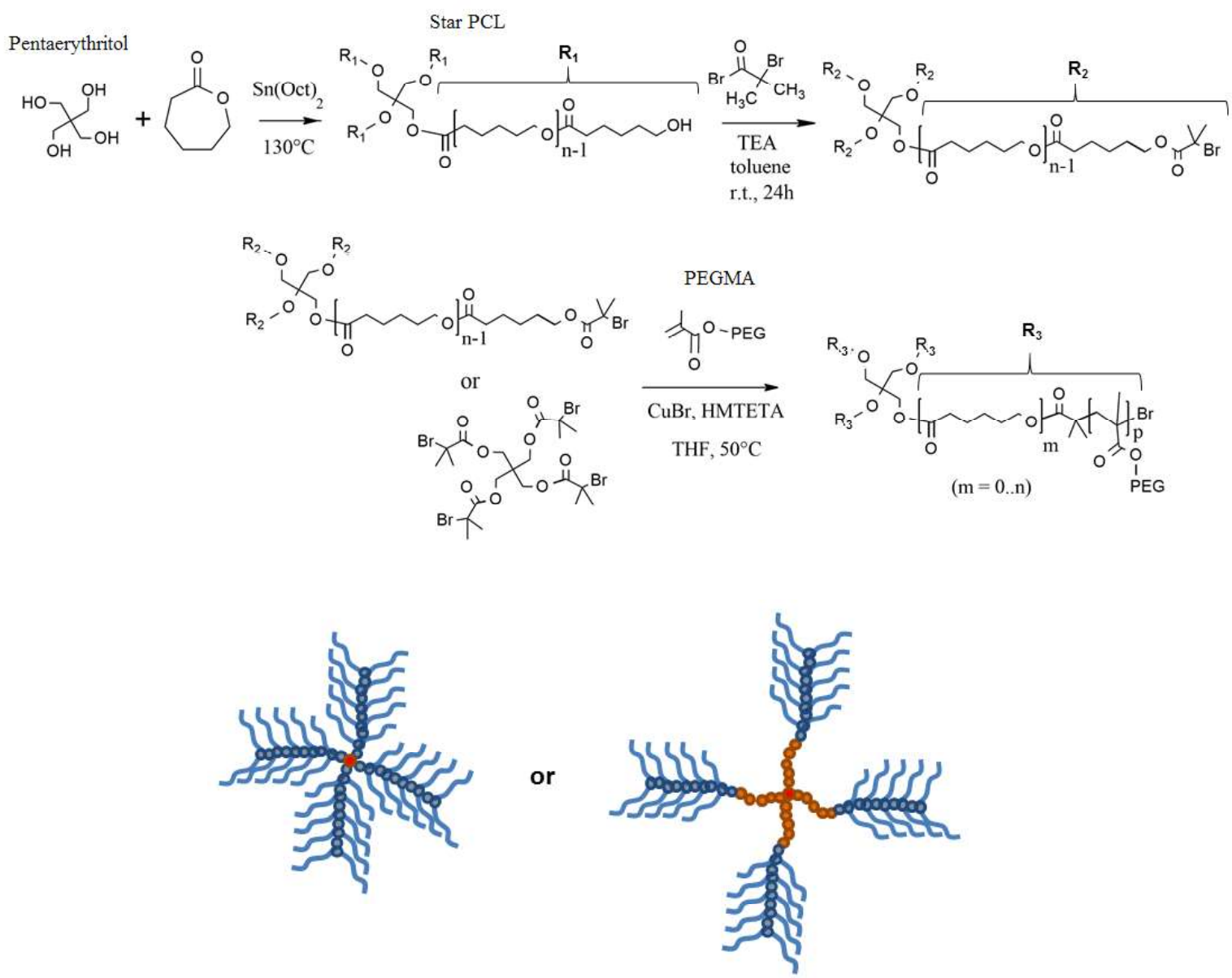
Scheme 2. Summary of the reactions involved with the synthesis of the polymeric nanocarriers.

The semilogarithmic kinetic plots obtained by ${ }^{1} \mathrm{H}$ NMR analysis (Figure 1A) and the molar mass versus conversion (Figure 1B) revealed first-order kinetics, as expected for a controlled radical polymerisation process. GPC analysis confirmed that the polymers maintained a narrow dispersity $(\mathrm{D}<1.2)$ during ATRP (Figure 1B and 1C).

A

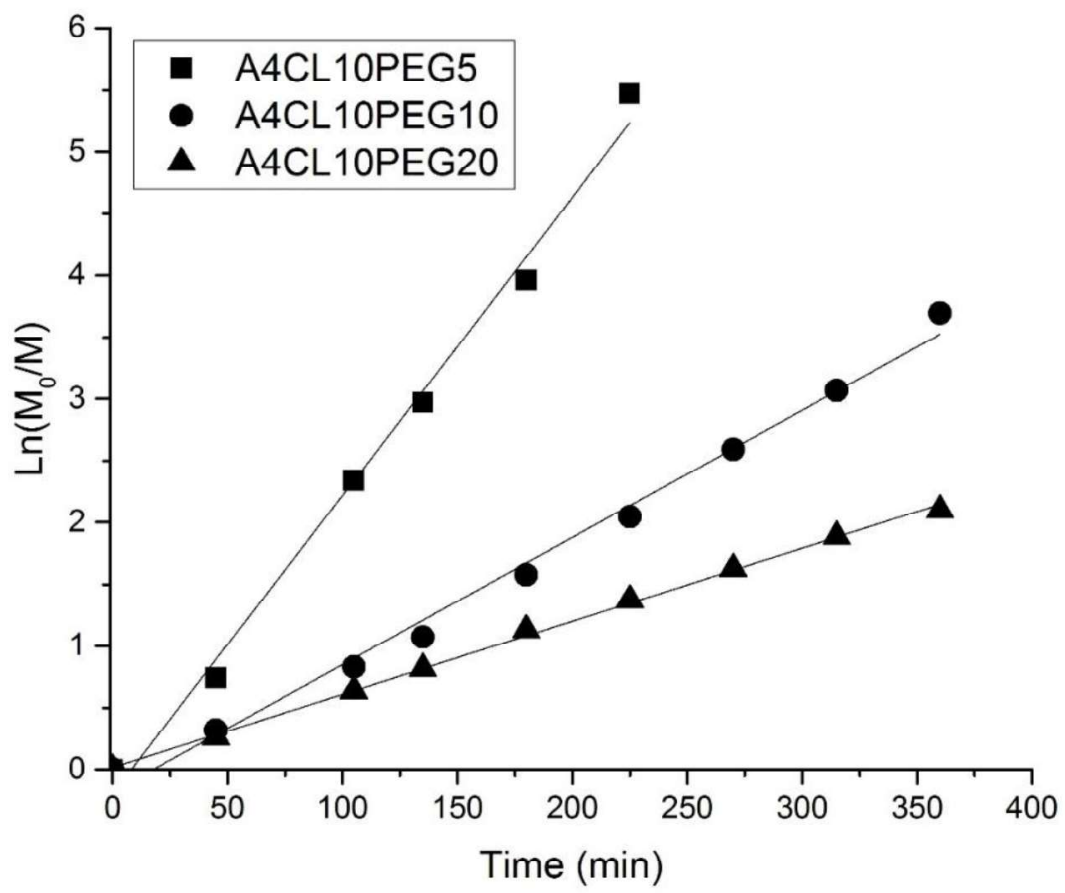



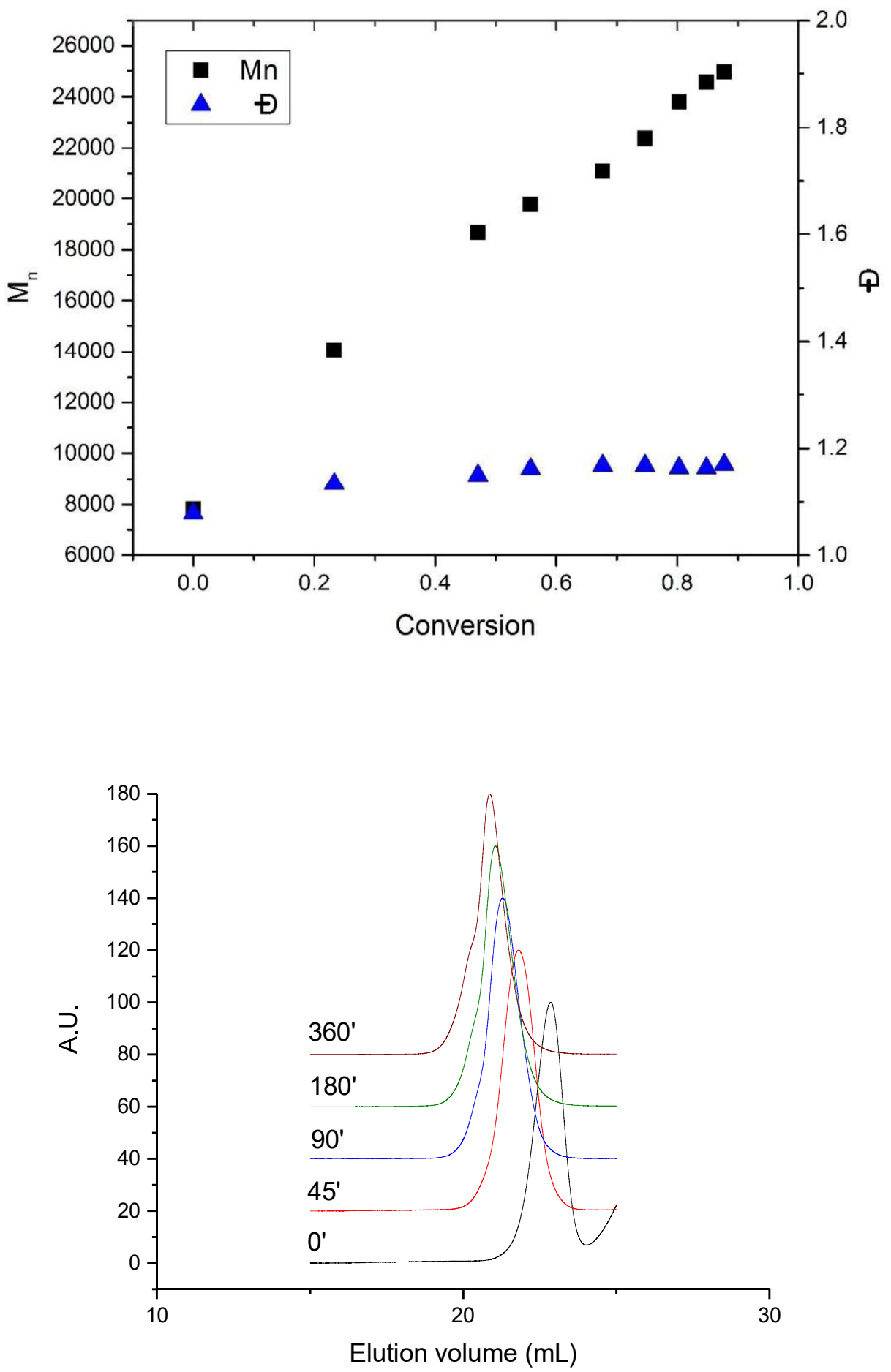

Figure 1. A) Kinetic plot of $\ln \left(\left[\mathrm{M}_{0}\right] /[\mathrm{M}]\right)$ versus time for ATRP of PEGMA (DP $\left.=5,10,20\right)$ using A4CL10Br as macroinitiator. B) $M \mathrm{n}$ and dispersity $\left(\mathrm{Ð}=\mathrm{M}_{\mathrm{w}} / \mathrm{Mn}_{\mathrm{n}}\right)$ vs conversion for A4CL10PEG20 polymerisation. C) GPC chromatograms of A4CL10PEG20 as function of reaction time. 
${ }^{1} \mathrm{H}$ NMR spectra of the star PCL macromolecule and its corresponding PCL macroinitiator is reported in Figure 2. The complete disappearance of the methylene signal adjacent to the hydroxyl group $(f, 3.63 \mathrm{ppm})$ and the appearance of the new signal of methylene adjacent to bromoisobutyrate $(g, 4.15 \mathrm{ppm})$ indicates the quantitative conversion of the multiarm PCL to ATRP macroinitiator. After ATRP, the proton signals of the methoxy end group of the PEGMA appears at $(1,3.37 \mathrm{ppm})$, together with the protons of the methyl group of the polymeric backbone (h, $1.16-0.80 \mathrm{ppm})$. The integrals of these signals were compared with those of the PCL to determine the final degree of polymerisation of these polymers (Table 1).

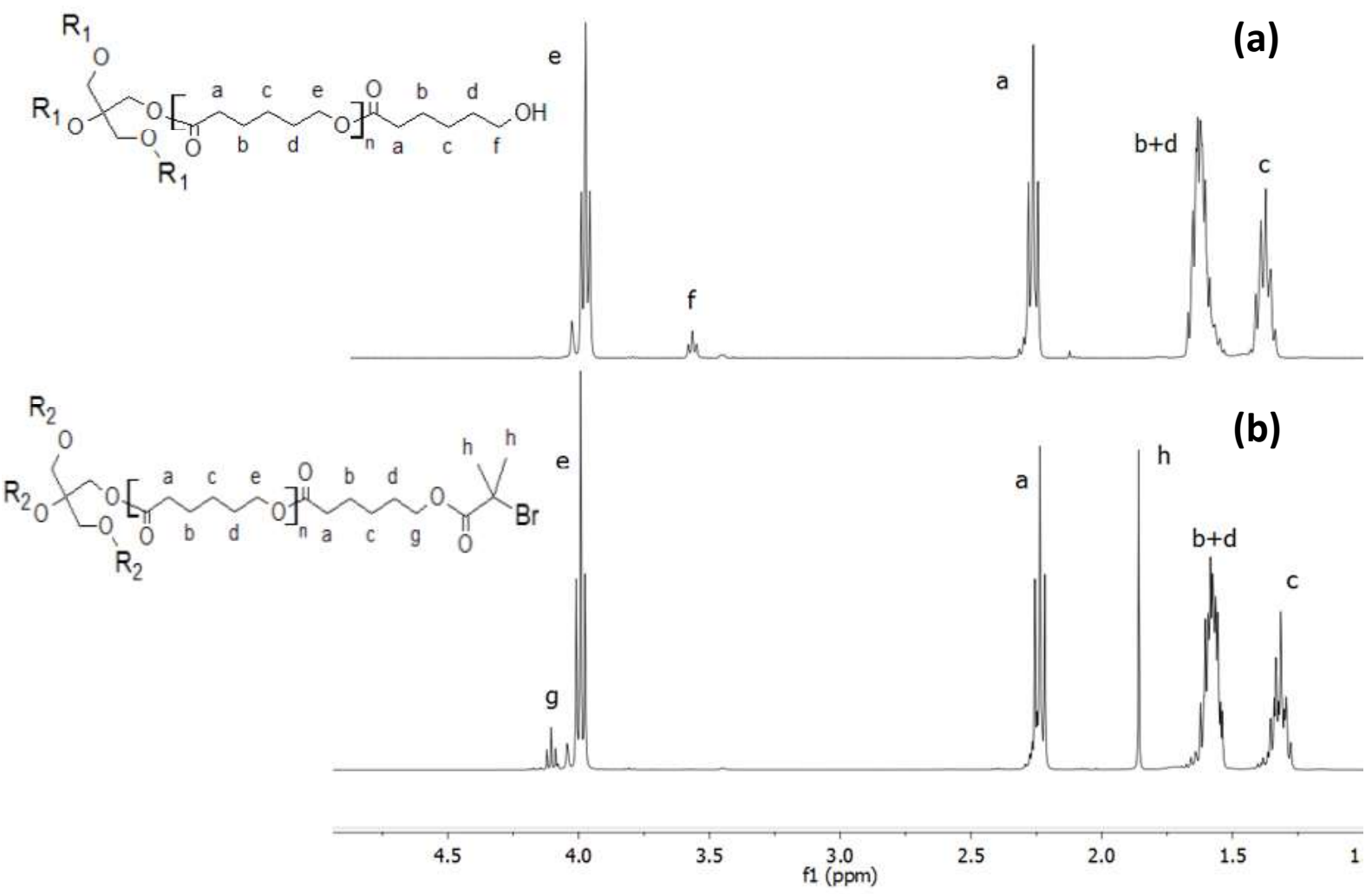




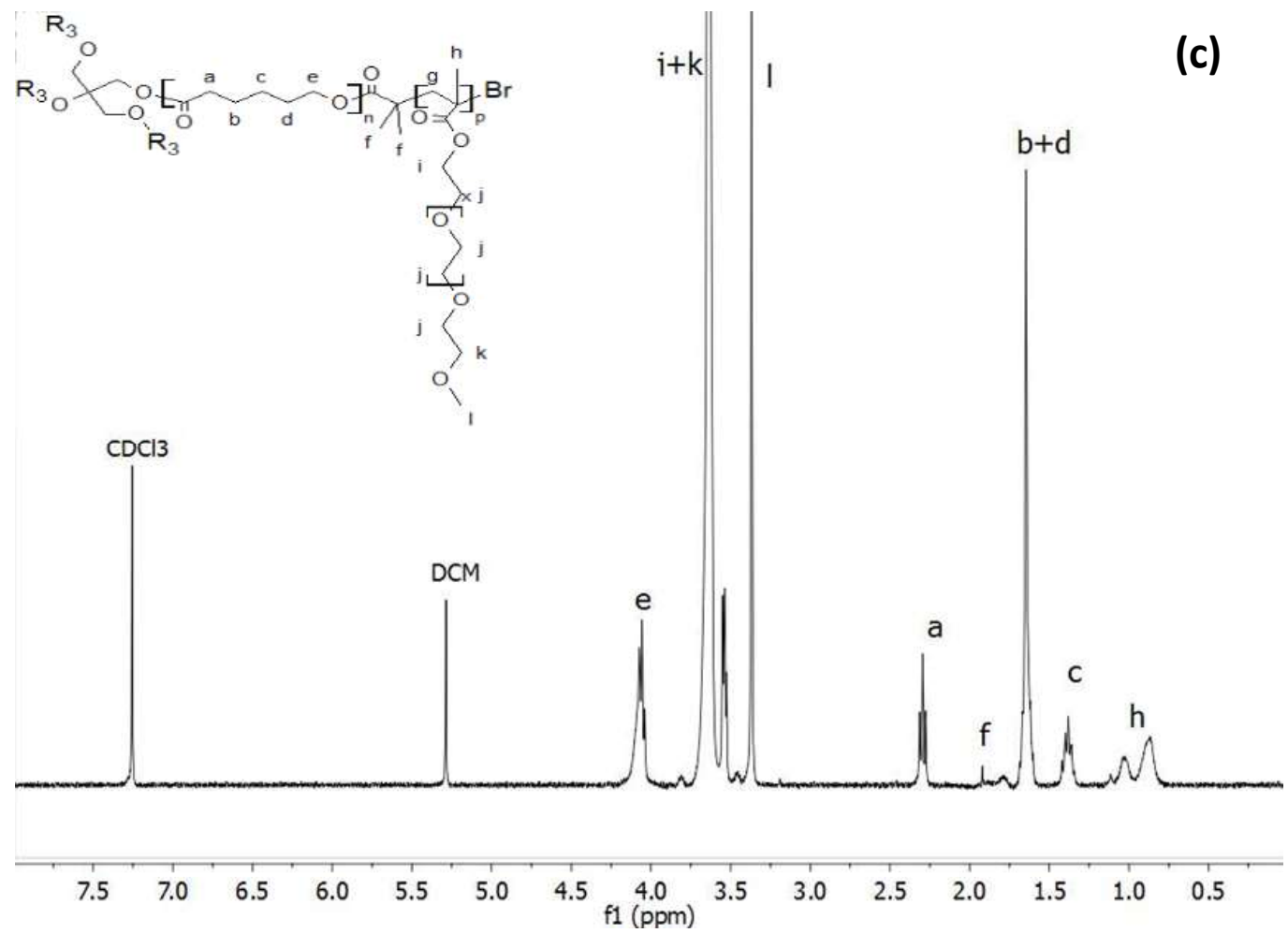

Figure 2. ${ }^{1} \mathrm{H}$ NMR spectra (in $\mathrm{CDCl}_{3}$ ) of A4CL10 (a), A4CL10Br (b), A4CL10PEG20 (c).

A library of star-shaped polymers with different lengths in hydrophobic core and hydrophilic shell were synthesised and characterised by NMR and GPC. Results are summarised in Table 1.

Table 1. Molecular weight determination of polymers by ${ }^{1} \mathrm{H}-\mathrm{NMR}$ and GPC. $\left({ }^{\dagger}\right)$ Theoretical degree of polymerisation (DP) per arm. $\left(^{*}\right)$ Conversion referred to the mols of $-\mathrm{OH}$ groups converted into ATRP initiators by esterification.

\begin{tabular}{lcccccc}
\hline \multicolumn{1}{c}{ Polymer } & DP of $\mathbf{C L}^{\dagger}$ & $\begin{array}{c}\text { DP of } \\
\text { PEGMA }^{\dagger}\end{array}$ & Conv [\%] & $\begin{array}{c}\text { Mn } \mathbf{~}^{\mathbf{1}} \mathbf{H}- \\
\text { NMR) }\end{array}$ & $\begin{array}{c}\text { Mn (GPC) } \\
\text { [g/mol] }\end{array}$ & Đ (GPC) \\
\hline A4CL10 & 10 & - & 100 & 4702 & 6494 & 1.17 \\
A4CL10Br & 10 & - & $100^{*}$ & 5298 & 8811 & 1.12 \\
A4CL20 & 20 & - & 100 & 9267 & 12072 & 1.18 \\
A4CL20Br & 20 & - & $100^{*}$ & 9863 & 12637 & 1.15 \\
\hline A4PEG5 & - & 5 & 100 & 10732 & 10686 & 1.18 \\
A4PEG10 & - & 10 & 99 & 20532 & 14206 & 1.17 \\
A4PEG20 & - & 20 & 93 & 37932 & 18865 & 1.13 \\
\hline A4CL10PEG5 & 10 & 5 & 83 & 14514 & 21485 & 1.21 \\
A4CL10PEG10 & 10 & 10 & 97 & 25614 & 23613 & 1.26 \\
A4CL10PEG20 & 10 & 20 & 87 & 41014 & 27300 & 1.15 \\
\hline A4CL20PEG5 & 20 & 5 & 74 & 17801 & 23246 & 1.20 \\
A4CL20PEG10 & 20 & 10 & 52 & 20801 & 23214 & 1.18 \\
A4CL20PEG20 & 20 & 20 & 90 & 46401 & 41281 & 1.26 \\
\hline
\end{tabular}


Once dispersed in aqueous solution, these polymers formed colloids of different hydrodynamic diameters, depending on the amount of CL and PEG repeating units, as revealed by DLS analysis (Table 2). The effect of temperature on particle size distribution was also assessed, in order to identify possible variation of the colloid properties from storage to in vitro and in vivo conditions.

Table 2. Dynamic light scattering analysis of the polymeric nanomaterials dispersed in PBS $10 \mathrm{mM} \mathrm{pH} 7.4$ (polymer concentration $1 \mathrm{mg} / \mathrm{mL}$ ) at different temperatures. The Z-average size is reported as hydrodynamic diameter $\mathrm{D}_{\mathrm{h}}, \mathrm{PdI}$ is the polydispersity index.

\begin{tabular}{|c|c|c|c|c|c|c|}
\hline Polymer & $\begin{array}{c}\text { PBS } 10^{\circ} \mathrm{C} \\
D_{h}[\mathrm{~nm}]\end{array}$ & $\begin{array}{c}\text { PBS } 10^{\circ} \mathrm{C} \\
\text { PdII }\end{array}$ & $\begin{array}{c}\text { PBS } 25^{\circ} \mathrm{C} \\
D_{h}[\mathrm{~nm}]\end{array}$ & $\begin{array}{c}\mathrm{PBS} \mathrm{25}^{\circ} \mathrm{C} \\
\text { PdI }\end{array}$ & $\begin{array}{c}\operatorname{PBS~37}^{\circ} \mathrm{C} \\
D_{h}[\mathrm{~nm}]\end{array}$ & $\begin{array}{c}\text { PBS 37 }{ }^{\circ} \mathrm{C} \\
\text { PdI }\end{array}$ \\
\hline A4PEG5 & 5.5 & 0.23 & 6.8 & 0.24 & 6.7 & 0.24 \\
\hline A4PEG10 & 6.1 & 0.21 & 7.6 & 0.16 & 8.4 & 0.25 \\
\hline A4PEG20 & 8.2 & 0.19 & 9.8 & 0.14 & 10.0 & 0.10 \\
\hline A4CL10PEG5 & 40.5 & 0.30 & 37.4 & 0.29 & 53.9 & 0.28 \\
\hline A4CL10PEG10 & 25.1 & 0.31 & 34.4 & 0.30 & 33.9 & 0.29 \\
\hline A4CL10PEG 20 & 20.5 & 0.21 & 22.9 & 0.22 & 26.4 & 0.22 \\
\hline A4CL20PEG5 & 80.9 & 0.17 & 103.9 & 0.19 & 122.6 & 0.18 \\
\hline A4CL20PEG10 & 55.4 & 0.17 & 71.41 & 0.16 & 80.51 & 0.17 \\
\hline A4CL20PEG20 & 68.5 & 0.24 & 85.0 & 0.24 & 118.6 & 0.32 \\
\hline
\end{tabular}

As expected, star polymers with no CL core (A4PEG-5,10,20) showed the smallest hydrodynamic diameters $\left(\mathrm{D}_{\mathrm{h}}<10 \mathrm{~nm}\right)$ in PBS. Polymers presenting a CL (DP 10) core showed colloids at a size range $20-50 \mathrm{~nm}$. This size decreases as the number of PEGMA repeating units increases, as an effect of the steric stabilisation of the hydrophilic PEG chains. The minimum size $\left(26.4 \mathrm{~nm}\right.$ at $\left.37^{\circ} \mathrm{C}\right)$ was obtained for the A4CL10PEG20 polymer. An effect of temperature on $D_{h}$ was also noticed in most of the samples; $D_{h}$ slightly increases as the temperature goes from 10 to $37^{\circ} \mathrm{C}$ and this may be ascribed to a lower critical solubility temperature (LCST) effect of PEG side chains[30] which may induce some temperature- 
dependent polymer association. Polymers with larger CL block (DP20) showed bigger aggregates (50 nm $\left.<\mathrm{D}_{\mathrm{h}}<120 \mathrm{~nm}\right)$, indicating a limited capability of the comb-like PEG blocks (with a DP 5 to 20) to prevent coil-coil interactions when the hydrophobic CL blocks are relatively long. The way these polymers aggregate may depend on several parameters, including the overall molecular weight, how the polymer chains self-assemble, and kinetic mechanisms where the diffusion coefficient of the colloids may play a role.

Taking into account our final goal to design nanocarriers which would be able to cross the GFB and reach podocytes, we selected from the library the three polymers A4PEG5, A4PEG20 and A4CL10PEG20 for biological tests as well as drug loading and release. The physical properties of the three polymers are summarised in Figure 3. A4PEG5 has an average number molecular weight of about $11 \mathrm{kDa}$ and a size of $6.7 \mathrm{~nm}$ at physiological conditions, which is approximately the same as albumin size[31] and therefore it should be able to cross the GFB. A4PEG20 has an Mn of about $38 \mathrm{kDa}$ and a size of $10 \mathrm{~nm}$, at borderline for GFB molecular weight and size cut-off[19, 20], but at least it should be able to cross GFB when pathologically damaged[21]. A4CL10PEG20 (Mn $\sim 41 \mathrm{kDa})$ presents a larger size distribution which may hinder GFB permeation, however its average size and polydispersity may be overestimated by DLS analysis, since pyrene tests indicated an apparent critical micelle concentration at $10^{-1} \mathrm{mg} / \mathrm{mL}$ (see Supplementary Material) which is far below the sample concentration used for scattering analysis. 


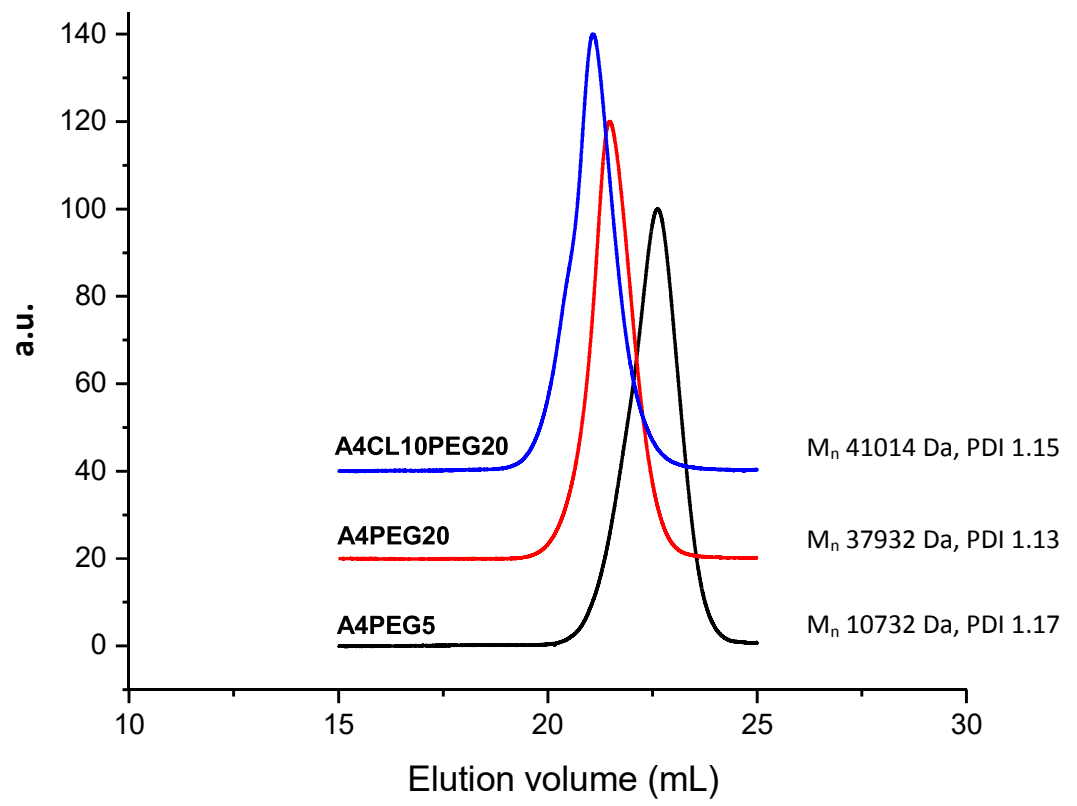

B

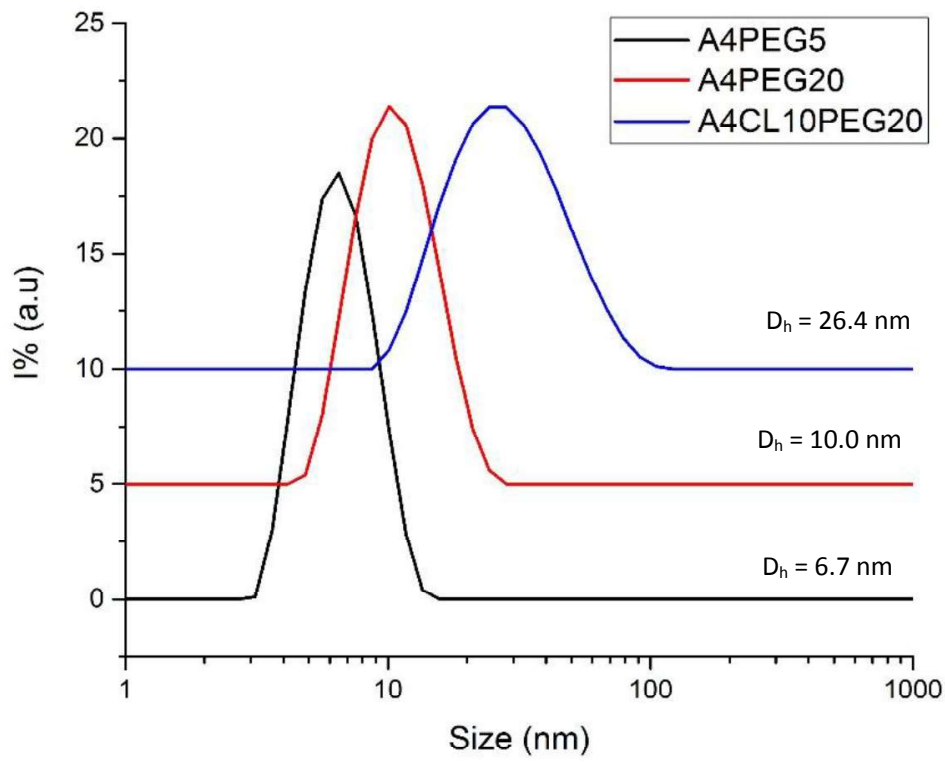

Figure 3. A) GPC analysis of A4PEG5, A4PEG20 and A4CL10PEG20. B) DLS curves of the selected polymers dispersed in PBS $10 \mathrm{mM} \mathrm{pH} 7.4$ at $37^{\circ} \mathrm{C}$. 
On the other hand A4CL10PEG20 has the advantage to have a hydrophobic polyester domain where a hydrophobic drug could be encapsulated in larger amounts than in A4PEG5 and A4PEG20. This important characteristic was confirmed by drug loading tests.

DEX was chosen for loading and release, firstly because it is a steroid with a proved efficacy in repairing podocytes $[11,32]$ (although the water-soluble dexamethasone phosphate is generally reported in literature) and secondly because its low molecular weight and high hydrophobicity are key characteristics for an efficient encapsulation in the nanomaterials[33]. DEX was encapsulated into the three polymers by nanoprecipitation/solvent (acetone) evaporation[34, 35]. The encapsulation efficiency (EE) and drug loading (DL) were determined by HPLC analysis (Table 3). Although polymers without CL core (A4PEG5 and A4PEG20) can still encapsulate DEX (EE $<5 \%$ and DL $<0.8 \%$ ) through the interaction between the drug molecule and the apolar carbon-carbon backbone[36], A4CL10PEG20 clearly achieved a higher DEX encapsulation (EE $>9 \%$ and DL 1.5\%) due to its CL domain. Particle size was not significantly affected by DEX loading (Table 3), in particular the average size of A4CL10PEG20 increased of only $2 \mathrm{~nm}$.

Table 3. Encapsulation efficiency (EE) and drug loading (DL) determined by HPLC after DEX loading tests. Average size and size polydispersity index measured by DLS before and after DEX encapsulation. Filtration yield is referred to \% polymer mass recovered after filtration.

\begin{tabular}{cccccccc}
\hline Polymer & $\begin{array}{c}\text { Filtration } \\
\text { yield } \\
\mathbf{\%}\end{array}$ & $\begin{array}{c}\text { EE } \\
\mathbf{( \% )}\end{array}$ & $\begin{array}{c}\text { DL } \\
\mathbf{( \% )}\end{array}$ & $\begin{array}{c}\mathbf{D}_{\mathbf{h}} \\
\text { before } \\
\text { loading }\end{array}$ & $\begin{array}{c}\text { PdI } \\
\text { before } \\
\text { loading }\end{array}$ & $\begin{array}{c}\mathbf{D}_{\mathbf{h}} \\
\text { after } \\
\text { loading }\end{array}$ & $\begin{array}{c}\text { PdI } \\
\text { after } \\
\text { loading }\end{array}$ \\
\hline A4CL10PEG20 & 72 & 9.1 & 1.5 & 26.4 & 0.22 & 28.2 & 0.25 \\
A4PEG20 & 81 & 4.6 & 0.6 & 10.0 & 0.10 & 7.2 & 0.14 \\
A4PEG5 & 61 & 4.9 & 0.8 & 6.7 & 0.24 & 5.4 & 0.17 \\
\hline
\end{tabular}


Drug release tests were carried out under sink conditions in PBS at $37^{\circ} \mathrm{C}$. Release profiles were followed by HPLC and are shown in Figure 4. Compared to A4CL10PEG20, smaller nanomaterials (A4PEG5 and A4PEG20) presented a faster release due to their higher surface area per mg of polymer. All polymers tested reached a DEX release plateau at approximately $24 \mathrm{~h}$.

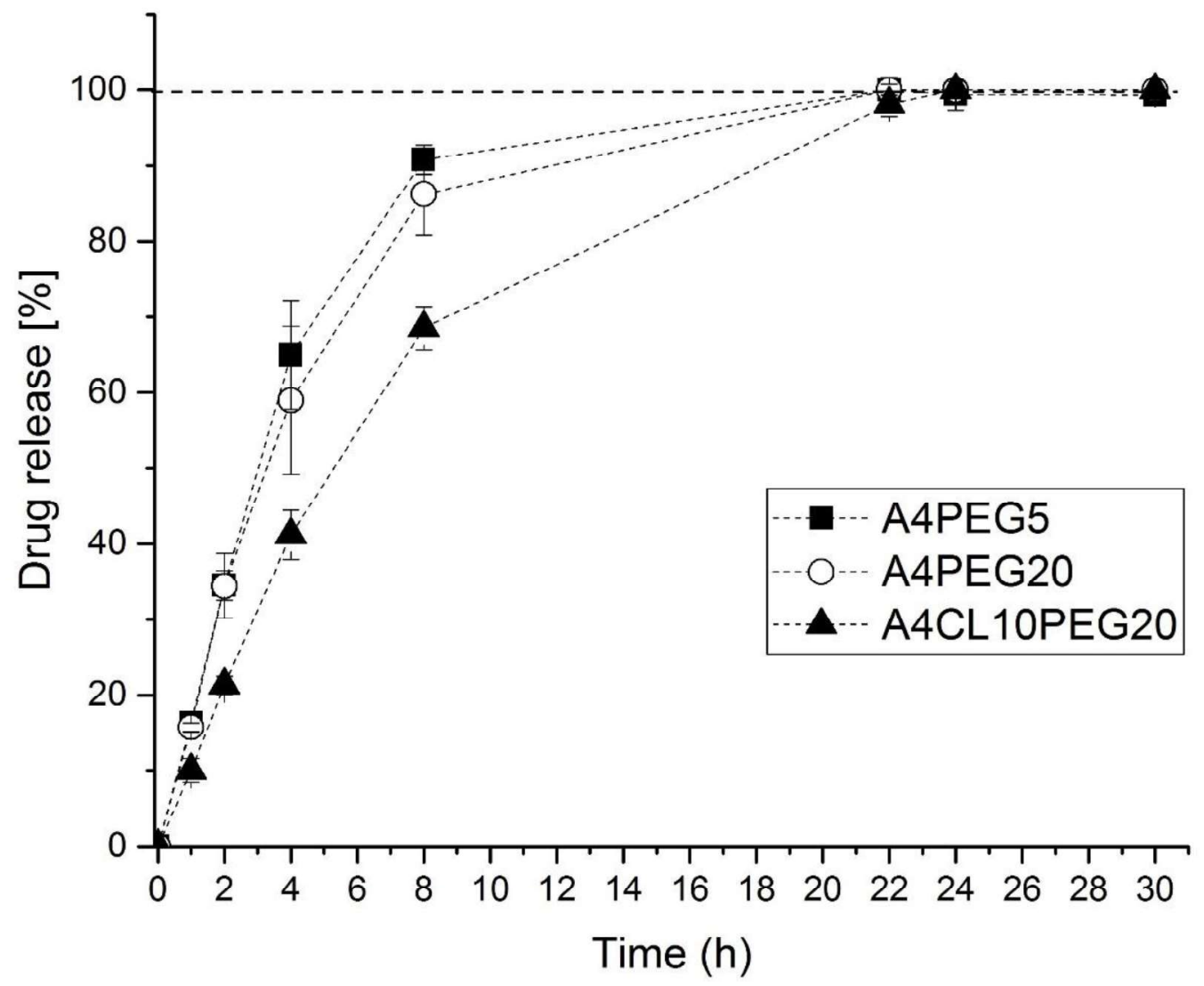

Figure 4. DEX release from polymer A4PEG5, A4PEG20 and A4CL10PEG20 in PBS at 37 ${ }^{\circ} \mathrm{C}$. Error bars indicate $\pm \mathrm{SD}$ from experiments run in triplicate. 


\subsection{In vitro nanotoxicity tests}

Cytotoxicity tests were firstly carried out in order to assess whether polymeric nanomaterials have a safe effect on podocytes, depending on composition, molecular weight, and concentration. SV1 cells were cultured at $37{ }^{\circ} \mathrm{C}$ with a medium containing different concentration of polymers $(0.01-2 \mathrm{mg} / \mathrm{mL})$ for 24 hours. Lactate Dehydrogenase (LDH) colorimetric assay was used to quantify the amount of the cytosolic enzyme lactate dehydrogenase released by damaged cells as an indicator of cellular toxicity. All polymeric nanocarries showed a safe cytotoxic profile up to a concentration of $1 \mathrm{mg} / \mathrm{mL}$ (Figure 5), which confirms the high biocompatibility of PCL- and PEG- based nanomaterials. As positive control, a 4-arm positively charged polymer A4TMA20 was synthesised (see Supplementary Material for details). This material showed a marked cytotoxic effect at concentrations above $0.05 \mathrm{mg} / \mathrm{mL}$, due to their strong electrostatic interaction with cell membrane and consequent damage[37]. Further MTT cytotoxicity tests on the nanomaterials and LDH test on DEX-loaded A4CL10PEG20 (Supplementary Material Figure S5 and S6, respectively) also confirm the safe cytotoxic profile of these polymeric nanocarriers.

A

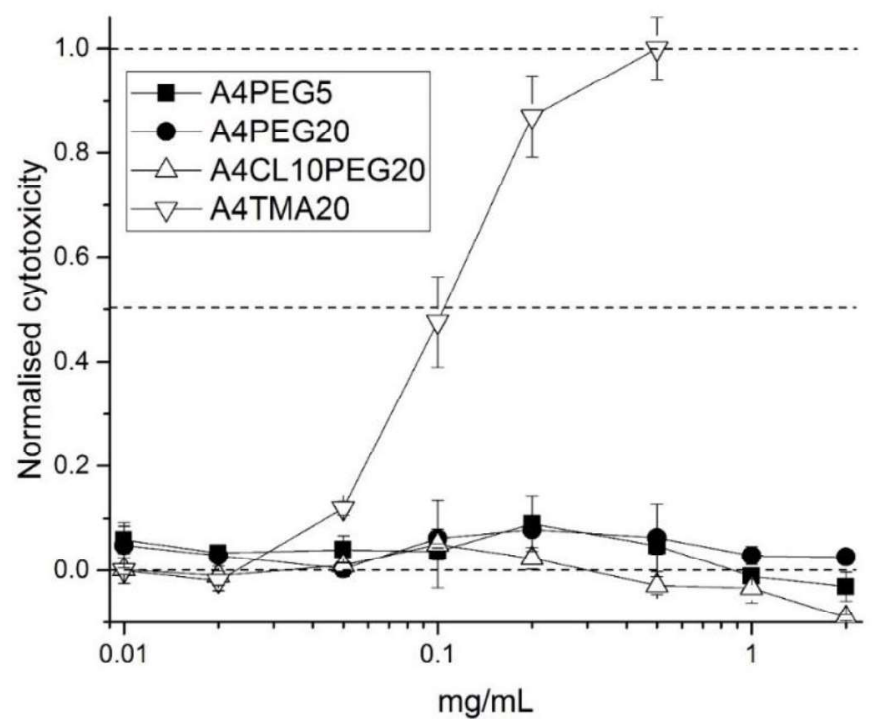



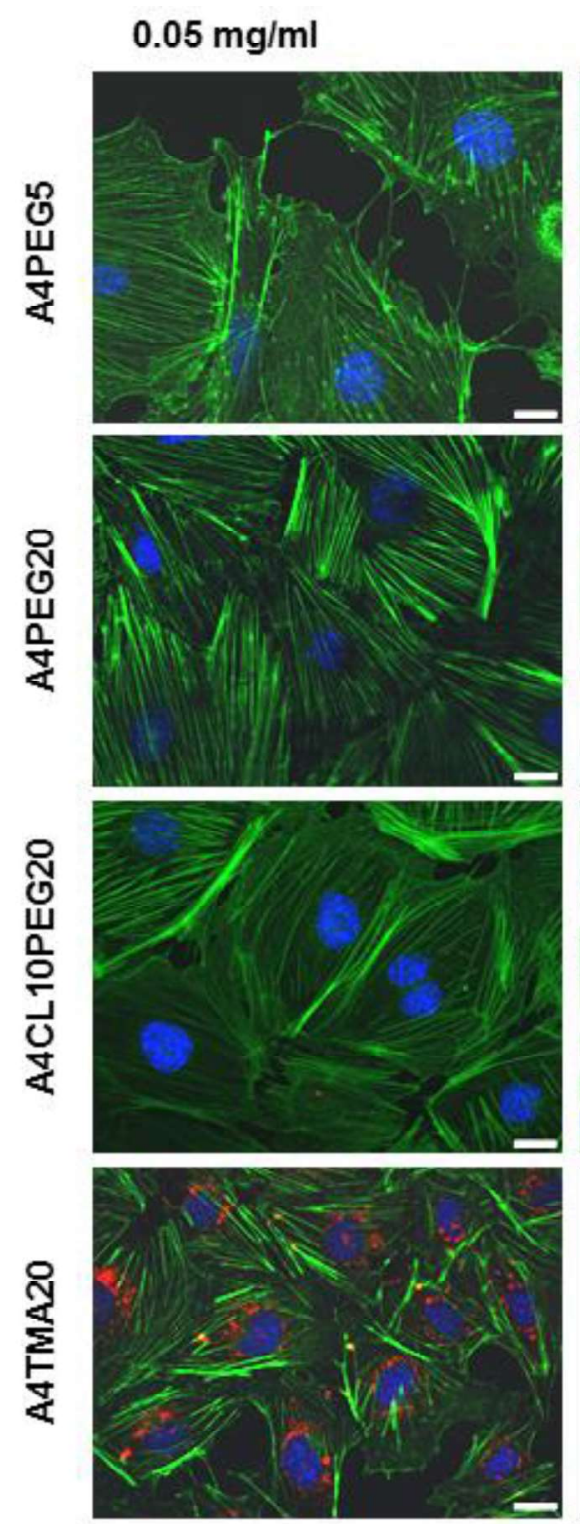

\section{$0.5 \mathrm{mg} / \mathrm{ml}$}
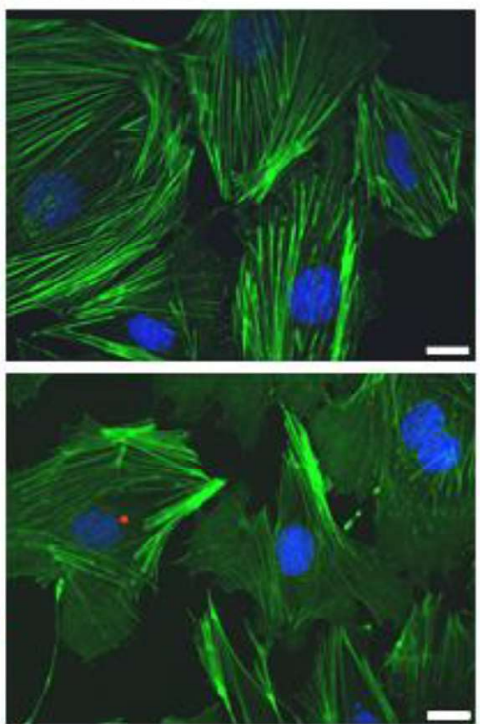

$1 \mathrm{mg} / \mathrm{ml}$
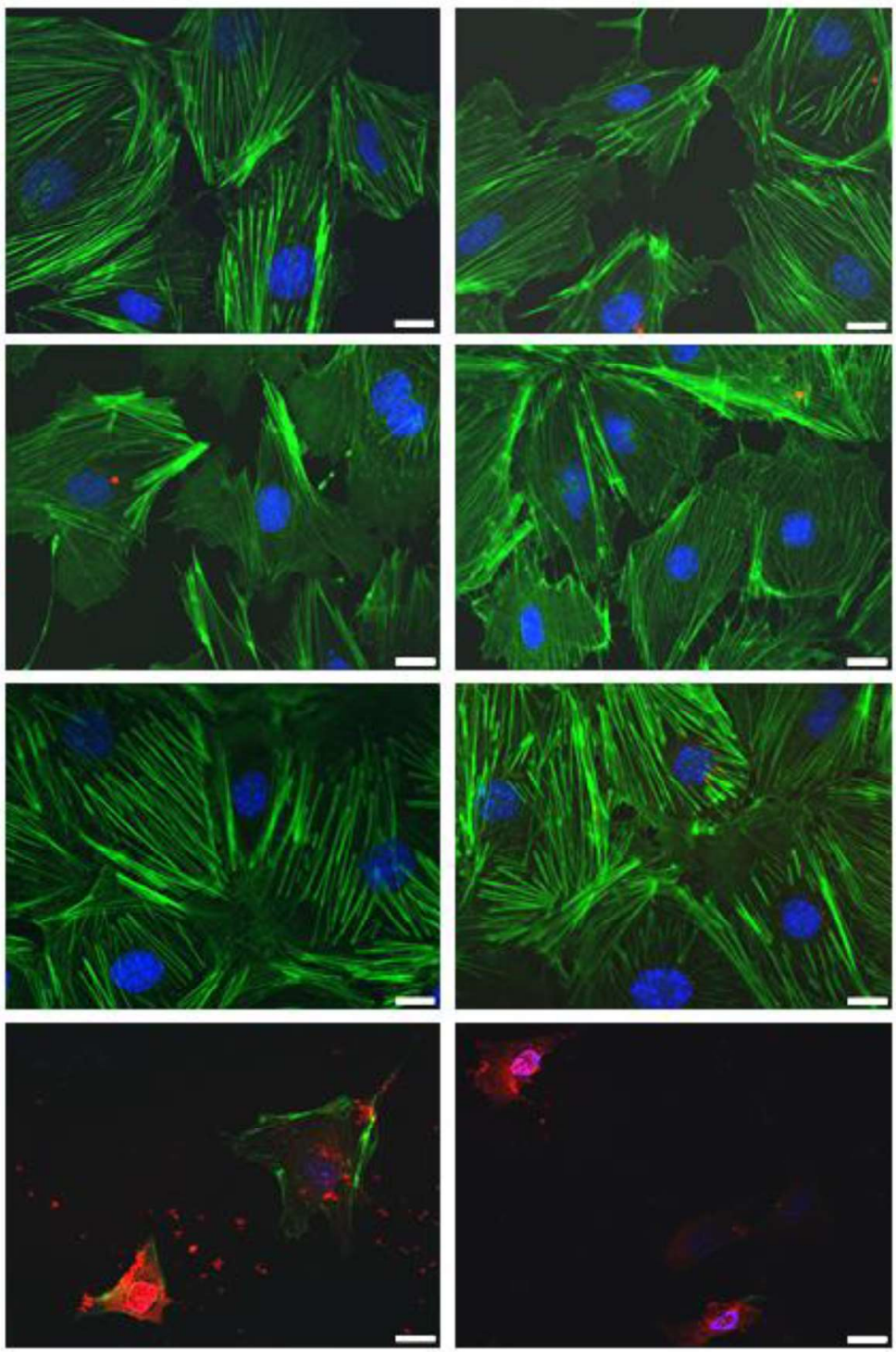

Figure 5. A) LDH assay on murine podocytes (SV1) incubated with polymers A4PEG5, A4PEG20, A4CL10PEG20, A4TMA20 for $24 \mathrm{~h}$, at concentration from 0.01 to $2 \mathrm{mg} / \mathrm{mL}$. Yaxis: Normalised Cytotoxicity $=($ Test sample-Low control $) /($ High control-Low control $)$; Low control: normal cells; High control: cells treated with lysis buffer.

B) Phalloidin staining (green) of filamentous actin in podocytes after $24 \mathrm{~h}$ polymer exposure (A4PEG5, A4PEG20, A4CL10PEG20, A4TMA20, red staining) at different concentrations (0.05 mg/mL, $0.5 \mathrm{mg} / \mathrm{mL}, 1 \mathrm{mg} / \mathrm{mL})$. Scale bar $20 \mu \mathrm{m}$. 
Fluorescence microscopy was also used to evaluate the effect of nanomaterial exposure on cell morphology and possible actin cytoskeleton rearrangements. In fact, alterations in the actin cytoskeleton are generally a sign of podocyte stress in response to chemical and biological stimuli[38, 39], including nanomaterial interactions with cell membrane and/or internalisation, even at concentrations where no cytotoxicity was observed. All polymeric materials did not seem to alter actin fibre density and orientation significantly, even at high concentration (up to $1 \mathrm{mg} / \mathrm{mL}$ ) (Figure 5). On the other hand, the positively charged polymer A4TMA20 induced a marked internalisation at low concentrations (high presence of red fluorescence spots, corresponding to the rhodaminated polymer, around cell nuclei) and a clear cell damage at concentration above $0.5 \mathrm{mg} / \mathrm{mL}$ (Figure 5), which may be ascribed to the effect of a strong electrostatic interaction between the nanomaterial and cell membrane.

\subsection{Podocyte repair by DEX release}

Taking into account the safe nanotoxicity profile of these polymers, we investigated the effect of the drug nanodelivery on podocyte repair. The sustained therapeutic effects of nanoencapsulated drugs was demonstrated on cultures of podocytes, whose damage was induced in vitro by Adriamycin (doxorubicin hydrochloride) incubation for $24 \mathrm{~h}[27,39,40]$. Damaged podocytes displayed shortened cell processes and substantial remodelling of the actin cytoskeleton, with loss of filament bundles and rounding of the cell shape[27, 39](Figure 6).

Due to its highest drug encapsulation efficiency, A4CL10PEG20 was selected for drug delivery tests. The effect of DEX release on podocytes is summarised in Figure 6 . Cytoskeleton damage, triggered by Adriamycin, was highlighted by staining actin fibres 
(green phalloidin), which were mostly localised in proximity of the cell membrane and their density was reduced within the cell body and around the nucleus. Actin filament alignment was quantified by FibrilTool[26], an ImageJ plug-in which was used to measure how well fibrils are ordered and report a score of anisotropy (Figure 6). When damaged cells were treated with DEX-loaded A4CL10PEG20 at high concentration (1 mg/mL, DEX $1.5 \% \mathrm{w} / \mathrm{w})$, they recovered the normal orientation of actin stress fibres in $24 \mathrm{~h}$ (Figure 6A). Lower nanocarrier concentration $(20 \mu \mathrm{g} / \mathrm{mL})$ showed a delayed response, since podocytes still presented cytoskeleton damage after $24 \mathrm{~h}$ incubation, but they recovered the normal orientation of actin stress fibres in $48 \mathrm{~h}$. This effect could be ascribed to the sustained delivery of DEX, since at low concentration nanocarriers take longer to release a sufficient amount of drug to stimulate fibre rearrangement. Primary podocytes were also tested to confirm the repairing efficacy of these nanocarriers, and we noticed that the cytoskeleton recovered its healthy morphology in $24 \mathrm{~h}$ for both nanocarrier concentrations (Figure 6B), with sprouting and elongation of podocyte cell processes[27]. 

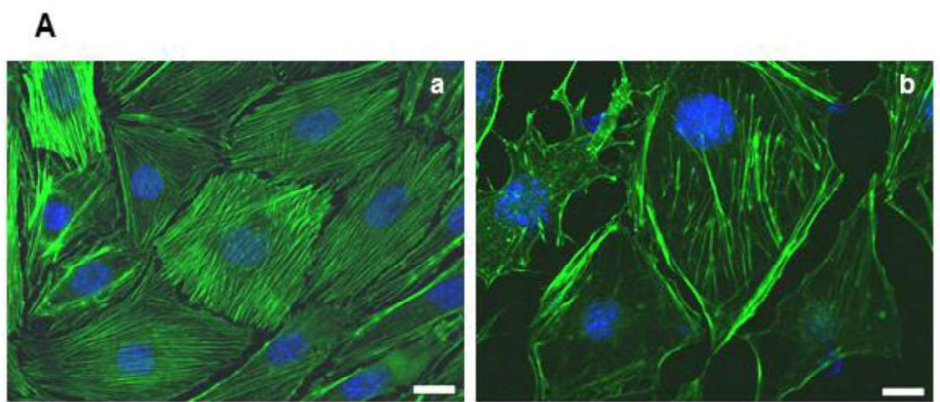

B
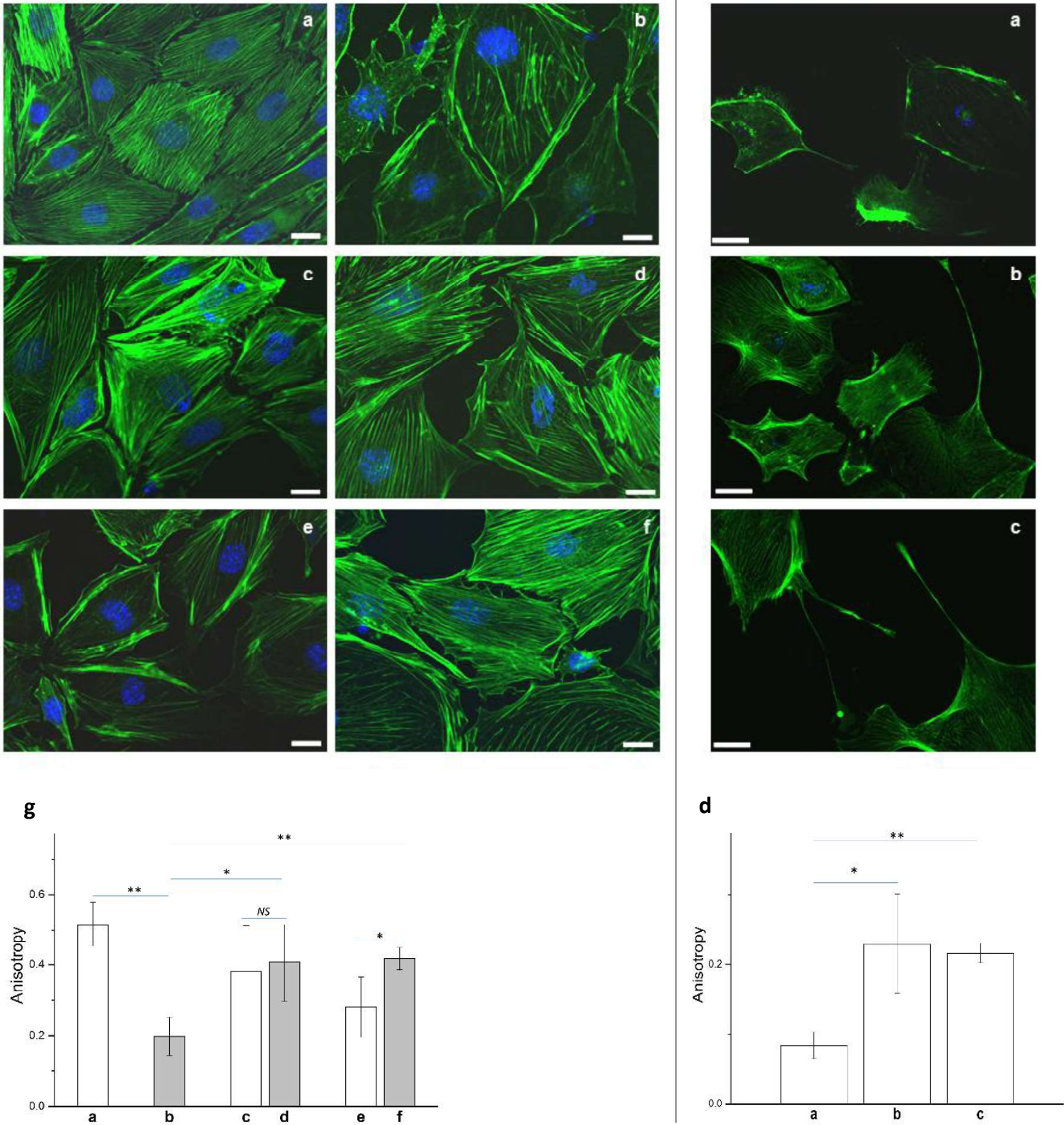

Figure 6. A) Podocytes ( $a$, control) were treated with Adriamycin $(b)$ to induce podocyte damage in vitro. Effect of DEX-loaded A4CL10PEG20 (polymer $1 \mathrm{mg} / \mathrm{mL}$, DEX $15 \mu \mathrm{g} / \mathrm{mL}$ ) incubated with podocytes for $24 \mathrm{~h}(c)$ and $48 \mathrm{~h}(d)$; cells recovered the normal orientation of actin stress fibres. Effect of less concentrated DEX-loaded A4CL10PEG20 (polymer 0.02 $\mathrm{mg} / \mathrm{mL}$, DEX $0.3 \mu \mathrm{g} / \mathrm{mL}$ ) incubated for $24 \mathrm{~h}(e)$ and $48 \mathrm{~h}(f)$ (Scale bar $20 \mu \mathrm{m})$. Quantification of actin filament alignment by Anisotropy scoring (g) of cells in images a-f. 
B) Adriamycin treatment $(a)$ of primary podocytes. Cells recovered the actin stress fibres orientation after $24 \mathrm{~h}$ treatment with DEX-loaded A4CL10PEG20 at a concentration of 1 $\mathrm{mg} / \mathrm{mL}(b$, DEX $15 \mu \mathrm{g} / \mathrm{mL})$ and $0.02 \mathrm{mg} / \mathrm{mL}(c$, DEX $0.3 \mu \mathrm{g} / \mathrm{ml})$, scale bar $20 \mu \mathrm{m}$. Anisotropy scoring (d) of actin filaments in images a-c.

\subsection{Drug testing in 3D co-culture system}

Besides classical 2D podocyte culture systems, a 3D co-culture in vitro models have the potential to provide important insights into cellular activities in response to nanomaterial exposure. We took advantage of a recently developed in vitro system based on a co-culture of endothelial cells and podocytes[22-24] to assess the mechanisms of nanomaterial interaction with a simplified version of the GFB.

The co-culture model is based on an isoporous membrane insert (i.e. a polyethyleneterephtalate (PET) semipermeable membrane with $1 \mu \mathrm{m}$ pore sizes), covered by podocytes and endothelial cells on the respective external and internal sides. PET membranes were coated on both sides with collagen type IV and podocytes and endothelial cells were seeded on the opposite sides [22-24] (Figure 7). The presence of the membrane between the two cell types allowed to perform separate assays in the two compartments and the functional assessment of albumin permeability through the membrane.

In order to establish whether the co-culture apparatus could respond to our polymeric drug delivery system, we tested the effect of DEX-loaded A4CL10PEG20 nanomaterial. Polymer concentrations were selected to achieve an optimal DEX concentration range below $100 \mu \mathrm{M}$, i.e. concentrations already reached in humans after intravenous injection and oral administration[41]. Firstly, the co-culture was treated with Adriamycin for $24 \mathrm{~h}$, and a clear increase of albumin permeability was noticed, as an effect of cell damage induced by the drug. 
The co-culture system was then incubated with the DEX-loaded polymer, and this treatment led to progressive reduction of albumin permeability, that was not observed with medium alone at $24 \mathrm{~h}$ and $48 \mathrm{~h}$ of incubation (Figure 7B). In the first $24 \mathrm{~h}$, high concentration of nanomaterial $(0.5 \mathrm{mg} / \mathrm{mL}$, DEX $1.5 \% \mathrm{w} / \mathrm{w})$, was able to markedly reduce albumin permeability, compared with control and with low-concentrated carrier $(0.01 \mathrm{mg} / \mathrm{mL})$ which did not show significant effects. On the other hand, low concentration of nanomaterial $(0.01$ $\mathrm{mg} / \mathrm{mL}$ ) achieved a reduction of albumin permeability after $48 \mathrm{~h}$, which was comparable to the response to higher polymer concentration $(0.5 \mathrm{mg} / \mathrm{mL})$. This may indicate that the sustained release of DEX has a delayed effect at lower polymer/drug concentration.

It is noteworthy that the incubation with these DEX-loaded nanoparticles did not return albumin permeability to its initial value (prior Adriamycin treatment), but markedly reduced it below the control values. This result could be ascribed to an effect of DEX to stimulate a better reorganisation of cytoskeleton and amelioration of the cell contacts, with a consequent decrease of the membrane pore size/number.

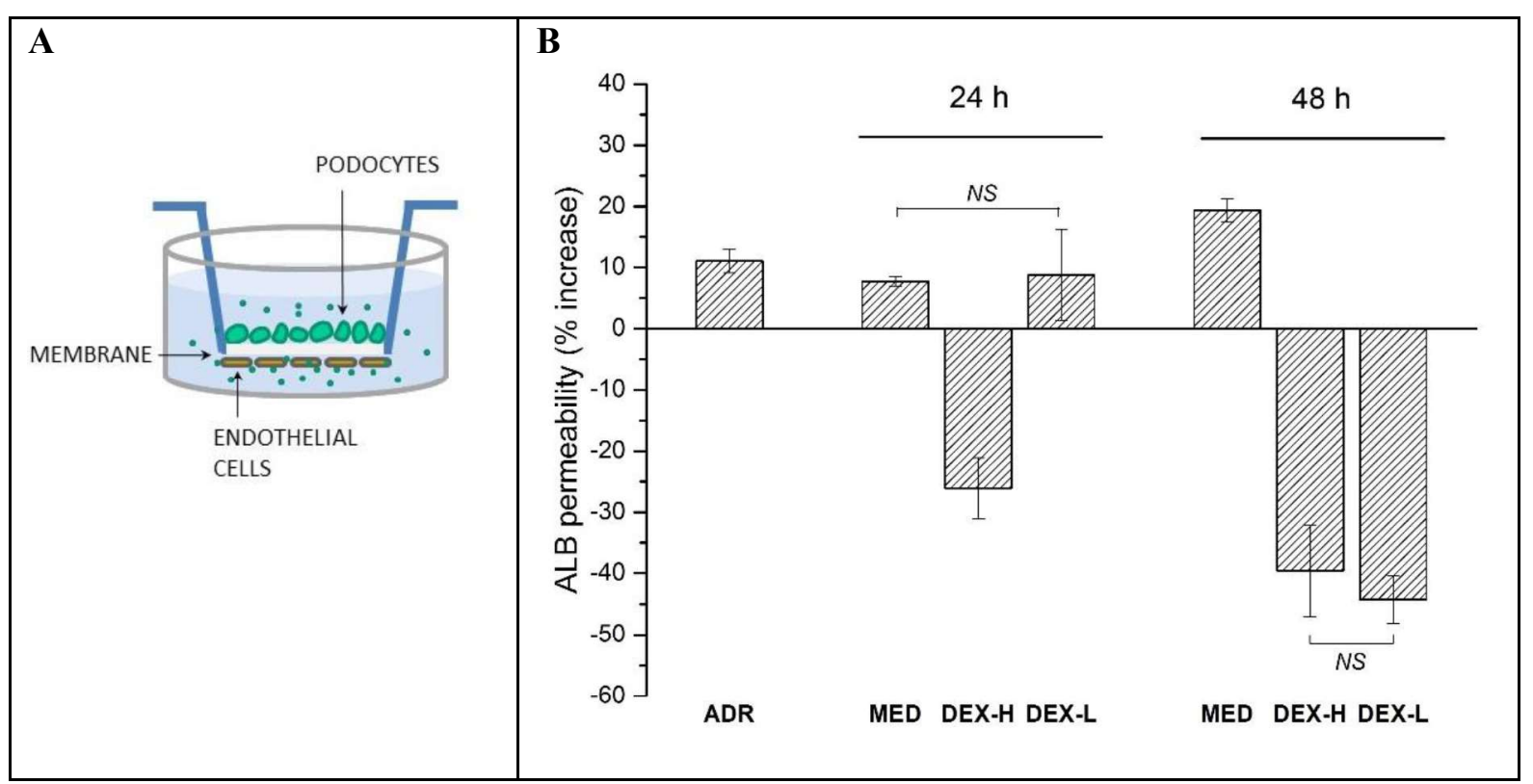

Figure 7. A) Sketch of the 3D co-culture system designed to mimic GFB in vitro. B) Percent increase of albumin (ALB) permeability following Adriamycin treatment (ADR), and recovery by $24 \mathrm{~h}$ and $48 \mathrm{~h}$ incubation with standard medium (MED), DEX-loaded A4CL10PEG20 at high concentration (DEX-H; A4CL10PEG20 $0.5 \mathrm{mg} / \mathrm{mL}$, DEX $1.5 \%$ 
$\mathrm{w} / \mathrm{w}$, corresponding to $20 \mu \mathrm{M}$ ), and at low concentration (DEX-L; A4CL10PEG20 0.01 $\mathrm{mg} / \mathrm{mL}$, DEX $1.5 \% \mathrm{w} / \mathrm{w}$, corresponding to $0.4 \mu \mathrm{M})(\mathrm{N}=3, N S$, not significant, $\mathrm{P}>0.1)$.

\subsection{In vivo tests}

The biodistribution of these polymeric nanocarriers in mice was assessed by fluorescence imaging of the dissected tissues. Figure 8 shows that in mice with Adriamycin induced nephropathy, kidney and lung accounted for minimum accumulation, whereas in liver and spleen the amount of the accumulated nanomaterials increased These results were comparable with the biodistribution obtained with healthy mice (Figure S7, Supplementary materials). The elevated accumulation in spleen is compatible with the mechanism of particle uptake by cells of the reticuloendothelial system (RES), particularly when the colloidal particles are PEGylated and present prolonged blood circulation[42, 43].

\section{A}
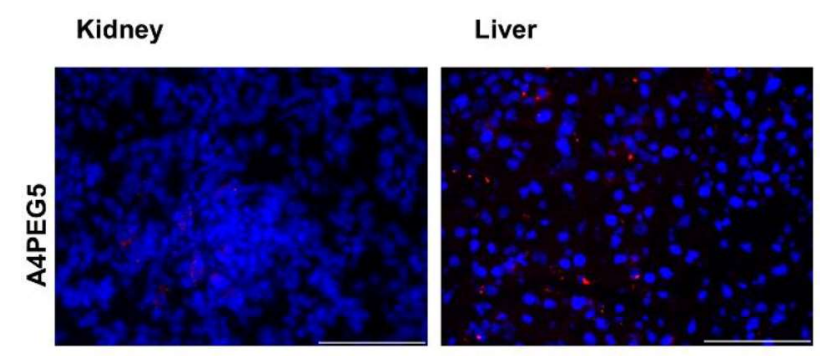

Lung

Spleen
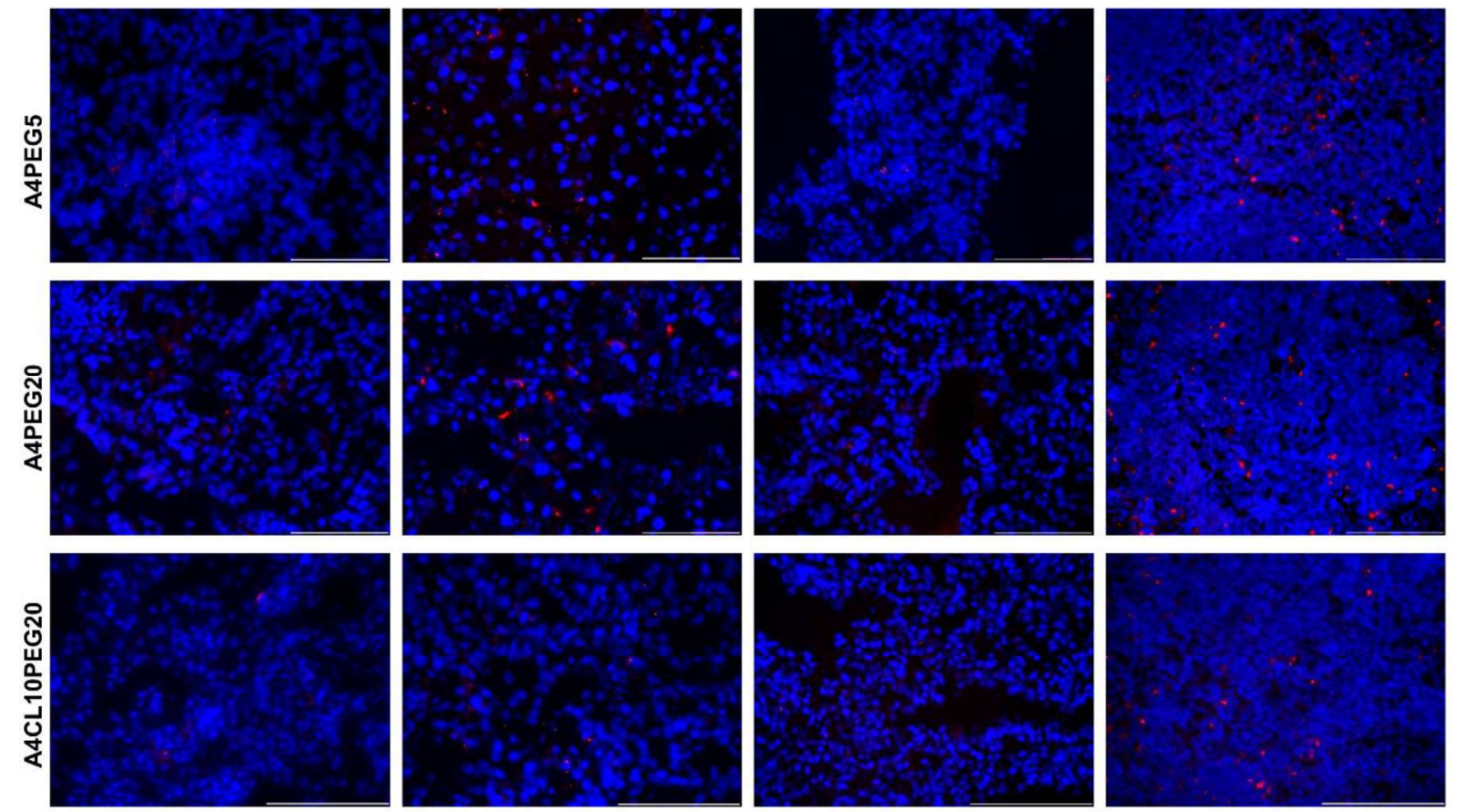

B
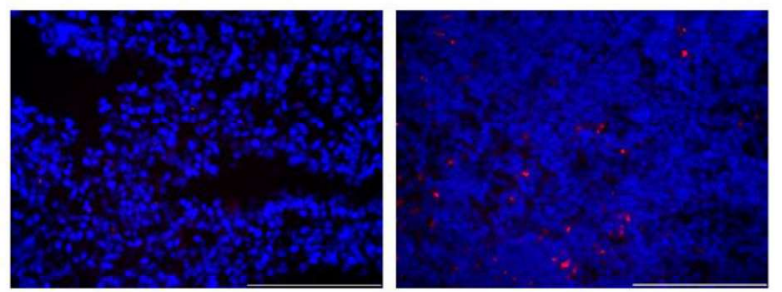


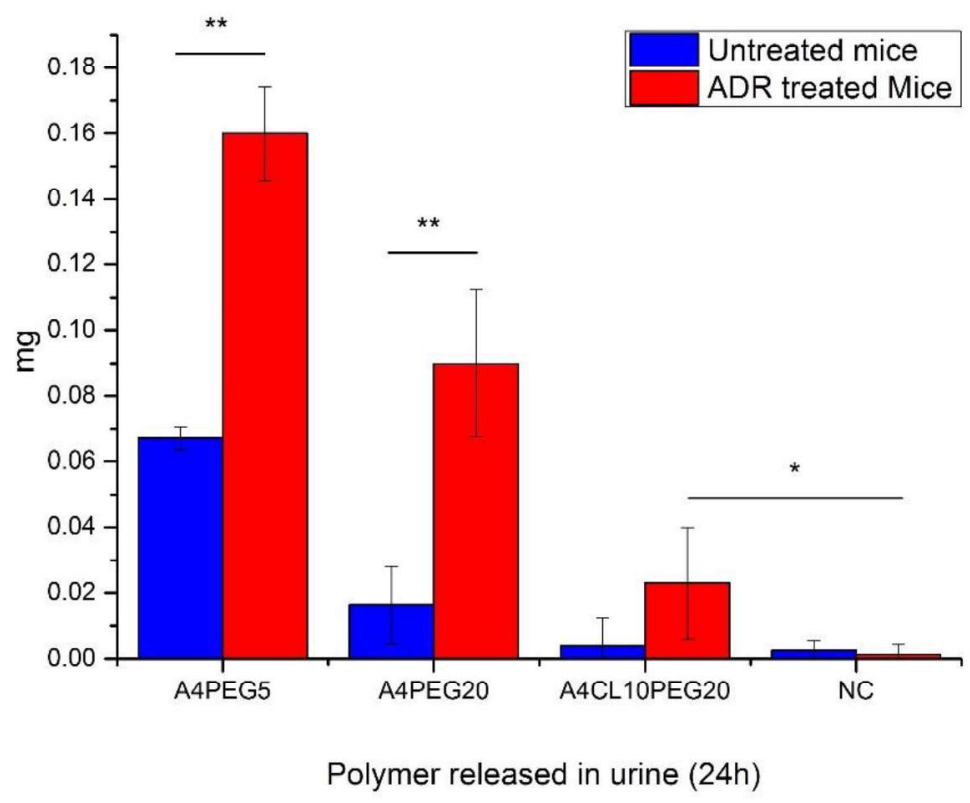

Figure 8. A) Presentation of fluorescence in tissues from different organs (kidney, liver, lung, spleen) of mice with ADR-induced nephropathy, after injection of polymeric nanocarriers (A4PEG5, A4PEG20, A4CL10PEG20) conjugated to rhodamine (red: RhB, polymers; blue: DAPI, nuclei). B) Amount of polymer detected in urine after 24h following nanomaterial injection $(\mathrm{N}=3, * P<0.05$ and $* * P<0.01)$.

Urine samples were collected to determine the amount of polymeric nanomaterial which was able to cross the GFB. In healthy mice, the amount of fluorescent nanoparticles measured in urine at $24 \mathrm{~h}$ was maximum for the smallest nanomaterial (A4PEG5) and minimum for the biggest (A4CL10PEG20). Kidney glomerulus damage was then induced in mice by Adriamycin treatment, according to a protocol previously described[27]. When urines were collected from these animals with induced nephropathy, the amount of detected nanomaterials considerably increased (up to $40 \% \mathrm{w} / \mathrm{w}$ of the injected dose in $24 \mathrm{~h}$ for A4PEG5) as an effect of GFB damage and consequent increase of its molecular weight cutoff[43]. Notably, a certain permeability of the large A4CL10PEG20 was also detected in Adriamycin treated mice. Taking into account that focal glomerulonephritis is characterised by focal tissue damage in kidney, as it affects a small proportion of renal glomeruli[44], we believe that by tuning the hydrodynamic diameter of the nanomaterial, a possible passive 
targeting may be obtained, as the carrier would be able to cross the GFB mainly at the site of damage.

\section{Conclusions}

Ultrasmall colloidal nanocarriers of tuneable size $(5-30 \mathrm{~nm})$ with/without a hydrophobic PCL core and a brush-like PEG corona were successfully obtained from four-arm star-shaped polymers, synthesised by controlled/living polymerisations. Tests on podocytes indicated a safe nanotoxicity profile, and controlled nanodelivery of dexamethasone showed a marked capacity to repair cytoskeleton damage and reduce albumin permeability in in vitro GFB models. Nanomaterial accumulation and clearance were also assessed in mice under physiological and pathological conditions. By tuning their physicochemical properties, these nanocarriers were able to to cross the GFB efficiently. These characteristics may pave the way for developing podocyte-targeted nanotherapeutics, increasing efficacy and limiting side effects of current therapies in CKD.

\section{Acknowledgements}

The financial support from Fondazione CEN - European Centre for Nanomedicine (Start-up package grant), co-funded by Regione Lombardia through the "Fondo per lo sviluppo e la coesione 2007-2013" is gratefully acknowledged.

The work was also supported by Fondazione Cariplo (grant n. 2013-1047, Nanoparticelle 2013), by Associazione Bambino Nefropatico ABN ONLUS, Milano, Italy, and by Fondazione La Nuova Speranza, Lotta alla Glomerulosclerosi Focale, Rho, Mi, Italy.

\section{References}


[1] V. Jha, G. Garcia-Garcia, K. Iseki, Z. Li, S. Naicker, B. Plattner, R. Saran, A.Y.-M. Wang, C.-W. Yang, Chronic kidney disease: global dimension and perspectives, The Lancet, 382 (2013) 260-272.

[2] J. Fort, Chronic renal failure: A cardiovascular risk factor, Kidney International, 68 (2005) 25-29.

[3] S. de Seigneux, P.Y. Martin, Management of patients with nephrotic syndrome, Swiss Medical Weekly, 139 (2009) 416-422.

[4] W.G. Couser, Glomerulonephritis, The Lancet, 353 (1999) 1509-1515.

[5] H. Holthofer, M.P. Rastaldi, Better kidney health for Europe, Journal of Nephrology, 19 (2006) 239-240.

[6] S.K. Sahoo, S. Parveen, J.J. Panda, The present and future of nanotechnology in human health care, Nanomedicine-Nanotechnology Biology and Medicine, 3 (2007) 20-31.

[7] J. Patrakka, K. Tryggvason, New insights into the role of podocytes in proteinuria, Nature Reviews Nephrology, 5 (2009) 463-468.

[8] F. Cellesi, M. Li, M.P. Rastaldi, Podocyte injury and repair mechanisms, Current Opinion in Nephrology and Hypertension, 24 (2015) 239-244.

[9] C. Faul, M. Donnelly, S. Merscher-Gomez, Y.H. Chang, S. Franz, J. Delfgaauw, J.M. Chang, H.Y. Choi, K.N. Campbell, K. Kim, J. Reiser, P. Mundel, The actin cytoskeleton of kidney podocytes is a direct target of the antiproteinuric effect of cyclosporine A, Nature Medicine, 14 (2008) 931-938.

[10] E. Gagliardini, D. Corna, C. Zoja, F. Sangalli, F. Carrara, M. Rossi, S. Conti, D. Rottoli, L. Longaretti, A. Remuzzi, G. Remuzzi, A. Benigni, Unlike each drug alone, lisinopril if combined with avosentan promotes regression of renal lesions in experimental diabetes, American Journal of Physiology-Renal Physiology, 297 (2009) F1448-F1456.

[11] C.Y. Xing, M.A. Saleem, R.J. Coward, L. Ni, I.R. Witherden, P.W. Mathieson, Direct effects of dexamethasone on human podocytes, Kidney International, 70 (2006) 1038-1045.

[12] A. Fornoni, J. Sageshima, C. Wei, S. Merscher-Gomez, R. Aguillon-Prada, A.N. Jauregui, J. Li, A. Mattiazzi, G. Ciancio, L. Chen, G. Zilleruelo, C. Abitbol, J. Chandar, W. Seeherunvong, C. Ricordi, M. Ikehata, M.P. Rastaldi, J. Reiser, G.W. Burke, III, Rituximab Targets Podocytes in Recurrent Focal Segmental Glomerulosclerosis, Science Translational Medicine, 3 (2011).

[13] E. Schoenenberger, J.H. Ehrich, H. Haller, M. Schiffer, The podocyte as a direct target of immunosuppressive agents, Nephrology Dialysis Transplantation, 26 (2011) 18-24.

[14] W. Kriz, Podocytes as a target for treatment with ACE inhibitors and/or angiotensinreceptor blockers, Kidney International, 65 (2004) 333-334.

[15] K. Pollinger, R. Hennig, M. Breunig, J. Tessmar, A. Ohlmann, E.R. Tamm, R. Witzgall, A. Goepferich, Kidney Podocytes as Specific Targets for cyclo(RGDfC)-Modified Nanoparticles, Small, 8 (2012) 3368-3375.

[16] C.H.J. Choi, J.E. Zuckerman, P. Webster, M.E. Davis, Targeting kidney mesangium by nanoparticles of defined size, Proceedings of the National Academy of Sciences of the United States of America, 108 (2011) 6656-6661.

[17] A.V. Nair, E.J. Keliher, A.B. Core, D. Brown, R. Weissleder, Characterizing the Interactions of Organic Nanoparticles with Renal Epithelial Cells in Vivo, ACS Nano, 9 (2015) 3641-3653.

[18] B. Haraldsson, J. Nyström, W.M. Deen, Properties of the Glomerular Barrier and Mechanisms of Proteinuria, Physiological Reviews, 88 (2008) 451-487.

[19] C. Brede, V. Labhasetwar, Applications of Nanoparticles in the Detection and Treatment of Kidney Diseases, Advances in Chronic Kidney Disease, 20 (2013) 454-465.

[20] A. Ruggiero, C.H. Villa, E. Bander, D.A. Rey, M. Bergkvist, C.A. Batt, K. ManovaTodorova, W.M. Deen, D.A. Scheinberg, M.R. McDevitt, Paradoxical glomerular filtration of 
carbon nanotubes, Proceedings of the National Academy of Sciences, 107 (2010) 1236912374.

[21] J. Tencer, I.-M. Frick, B.W. Öquist, P. Alm, B. Rippe, Size-selectivity of the glomerular barrier to high molecular weight proteins: Upper size limitations of shunt pathways, Kidney International, 53 (1998) 709-715.

[22] M.P.V.G.m. Rastaldi, I-20017 RHO (MI), IT), LI, Min (Via Carlo Perini 21, I-20157 Milano, IT), METHOD FOR THE THREE-DIMENSIONAL CO- CULTURE OF PODOCYTES AND ENDOTHELIAL CELLS AND RELATIVE IN VITRO COCULTURE SYSTEM, in, Fondazione, Irccs, 2012.

[23] M. Li, A. Corbelli, S. Watanabe, S. Armelloni, M. Ikehata, V. Parazzi, C. Pignatari, L. Giardino, D. Mattinzoli, L. Lazzari, A. Puliti, F. Cellesi, C. Zennaro, P. Messa, M.P. Rastaldi, Three-dimensional podocyte-endothelial cell co-cultures: Assembly, validation, and application to drug testing and intercellular signaling studies, European Journal of Pharmaceutical Sciences, 86 (2016) 1-12.

[24] C. Colombo, M. Li, S. Watanabe, P. Messa, A. Edefonti, G. Montini, D. Moscatelli, M.P. Rastaldi, F. Cellesi, Polymer Nanoparticle Engineering for Podocyte Repair: From in Vitro Models to New Nanotherapeutics in Kidney Diseases, ACS Omega, 2 (2017) 599-610.

[25] C.A. Schneider, W.S. Rasband, K.W. Eliceiri, NIH Image to ImageJ: 25 years of image analysis, Nat Meth, 9 (2012) 671-675.

[26] A. Boudaoud, A. Burian, D. Borowska-Wykret, M. Uyttewaal, R. Wrzalik, D. Kwiatkowska, O. Hamant, FibrilTool, an ImageJ plug-in to quantify fibrillar structures in raw microscopy images, Nat Protoc, 9 (2014) 457-463.

[27] M. Li, S. Armelloni, C. Zennaro, C. Wei, A. Corbelli, M. Ikehata, S. Berra, L. Giardino, D. Mattinzoli, S. Watanabe, C. Agostoni, A. Edefonti, J. Reiser, P. Messa, M.P. Rastaldi, BDNF repairs podocyte damage by microRNA-mediated increase of actin polymerization, Journal of Pathology, 235 (2015) 731-744.

[28] O.G. Schramm, M.A.R. Meier, R. Hoogenboom, H.P. van Erp, J.-F. Gohy, U.S. Schubert, Polymeric nanocontainers with high loading capacity of hydrophobic drugs, Soft Matter, 5 (2009) 1662-1667.

[29] V. Coessens, T. Pintauer, K. Matyjaszewski, Functional polymers by atom transfer radical polymerization, Progress in Polymer Science, 26 (2001) 337-377.

[30] M.A. Ward, T.K. Georgiou, Thermoresponsive Polymers for Biomedical Applications, Polymers, 3 (2011) 1215-1242.

[31] A.I. Luik, Y.N. Naboka, S.E. Mogilevich, T.O. Hushcha, N.I. Mischenko, Study of human serum albumin structure by dynamic light scattering: two types of reactions under different $\mathrm{pH}$ and interaction with physiologically active compounds, Spectrochimica Acta Part a-Molecular and Biomolecular Spectroscopy, 54 (1998) 1503-1507.

[32] R.F. Ransom, N.G. Lam, M.A. Hallett, S.J. Atkinson, W.E. Smoyer, Glucocorticoids protect and enhance recovery of cultured murine podocytes via actin filament stabilization, Kidney International, 68 (2005) 2473-2483.

[33] V. Krishnan, X. Xu, S.P. Barwe, X. Yang, K. Czymmek, S.A. Waldman, R.W. Mason, X. Jia, A.K. Rajasekaran, Dexamethasone-Loaded Block Copolymer Nanoparticles Induce Leukemia Cell Death and Enhance Therapeutic Efficacy: A Novel Application in Pediatric Nanomedicine, Molecular Pharmaceutics, 10 (2013) 2199-2210.

[34] J. Cheng, B.A. Teply, I. Sherifi, J. Sung, G. Luther, F.X. Gu, E. Levy-Nissenbaum, A.F. Radovic-Moreno, R. Langer, O.C. Farokhzad, Formulation of functionalized PLGA-PEG nanoparticles for in vivo targeted drug delivery, Biomaterials, 28 (2007) 869-876.

[35] E. Sah, H. Sah, Recent Trends in Preparation of Poly(lactide-co-glycolide) Nanoparticles by Mixing Polymeric Organic Solution with Antisolvent, Journal of Nanomaterials, 2015 (2015) 22. 
[36] J.-F. Lutz, Polymerization of oligo(ethylene glycol) (meth)acrylates: Toward new generations of smart biocompatible materials, Journal of Polymer Science Part A: Polymer Chemistry, 46 (2008) 3459-3470.

[37] E. Froehlich, The role of surface charge in cellular uptake and cytotoxicity of medical nanoparticles, International Journal of Nanomedicine, 7 (2012) 5577-5591.

[38] G.I. Welsh, M.A. Saleem, The podocyte cytoskeleton-key to a functioning glomerulus in health and disease, Nature Reviews Nephrology, 8 (2012) 14-21.

[39] M. Schiffer, B. Teng, C. Gu, V.A. Shchedrina, M. Kasaikina, V.A. Pham, N. Hanke, S. Rong, F. Gueler, P. Schroder, I. Tossidou, J.-K. Park, L. Staggs, H. Haller, S. Erschow, D. Hilfiker-Kleiner, C. Wei, C. Chen, N. Tardi, S. Hakroush, M.K. Selig, A. Vasilyev, S. Merscher, J. Reiser, S. Sever, Pharmacological targeting of actin-dependent dynamin oligomerization ameliorates chronic kidney disease in diverse animal models, Nature Medicine, 21 (2015) 601-609.

[40] V.D.C. Teixeira, S.M. Blattner, M. Li, H.J. Anders, C.D. Cohen, I. Edenhofer, N. Calvaresi, M. Merkle, M.P. Rastaldi, M. Kretzler, Functional consequences of integrin-linked kinase activation in podocyte damage, Kidney International, 67 (2005) 514-523.

[41] A. Guess, S. Agrawal, C.-C. Wei, R.F. Ransom, R. Benndorf, W.E. Smoyer, Dose- and time-dependent glucocorticoid receptor signaling in podocytes, American Journal of Physiology-Renal Physiology, 299 (2010) F845-F853.

[42] M.T. Peracchia, E. Fattal, D. Desmaële, M. Besnard, J.P. Noël, J.M. Gomis, M. Appel, J. d'Angelo, P. Couvreur, Stealth ${ }^{\circledR}$ PEGylated polycyanoacrylate nanoparticles for intravenous administration and splenic targeting, Journal of Controlled Release, 60 (1999) 121-128.

[43] K. Avgoustakis, A. Beletsi, Z. Panagi, P. Klepetsanis, E. Livaniou, G. Evangelatos, D.S. Ithakissios, Effect of copolymer composition on the physicochemical characteristics, in vitro stability, and biodistribution of PLGA-mPEG nanoparticles, International Journal of Pharmaceutics, 259 (2003) 115-127.

[44] R.C. Wiggins, The spectrum of podocytopathies: A unifying view of glomerular diseases, Kidney International, 71 (2007) 1205-1214. 